\title{
Functionally Distinct Dopamine Signals in Nucleus Accumbens Core and Shell in the Freely Moving Rat
}

\author{
이akob K. Dreyer, ${ }^{1}$ Caitlin M. Vander Weele, ${ }^{2}$ Vedran Lovic, ${ }^{3}$ and Brandon J. Aragona ${ }^{4}$ \\ ${ }^{1}$ Department of Neuroscience and Pharmacology, University of Copenhagen, DK-2200 Copenhagen, Denmark, ${ }^{2}$ Department of Brain and Cognitive \\ Sciences, Massachusetts Institute of Technology, Cambridge, Massachusetts 02139, 3. Department of Psychology, The University of Calgary, Calgary, \\ Albertan T2N 1N4, Canada, and ${ }^{4}$ Department of Psychology, University of Michigan, Ann Arbor, Michigan 48109
}

Dynamic signaling of mesolimbic dopamine (DA) neurons has been implicated in reward learning, drug abuse, and motivation. However, this system is complex because firing patterns of these neurons are heterogeneous; subpopulations receive distinct synaptic inputs, and project to anatomically and functionally distinct downstream targets, including the nucleus accumbens (NAc) shell and core. The functional roles of these cell populations and their real-time signaling properties in freely moving animals are unknown. Resolving the real-time DA signal requires simultaneous knowledge of the synchronized activity of DA cell subpopulations and assessment of the down-stream functional effect of DA release. Because this is not yet possible solely by experimentation in vivo, we combine computational modeling and fast-scan cyclic voltammetry data to reconstruct the functionally relevant DA signal in DA neuron subpopulations projecting to the NAc core and shell in freely moving rats. The approach provides a novel perspective on real-time DA neuron firing and concurrent activation of presynaptic autoreceptors and postsynaptic targets. We first show that individual differences in DA release arise from differences in autoreceptor feedback. The model predicts that extracellular DA concentrations in NAc core result from constant baseline DA firing, whereas DA concentrations in NAc shell reflect highly dynamic firing patters, including synchronized burst firing and pauses. Our models also predict that this anatomical difference in DA signaling is exaggerated by intravenous infusion of cocaine.

Key words: autoreceptor; D1-receptor; D2-receptor; fast-scan cyclic voltammetry; raclopride; uptake inhibition

\section{Significance Statement}

Orchestrated signaling from mesolimbic dopamine (DA) neurons is important for initiating appropriate behavior in response to salient stimuli. Thus, subpopulations of mesolimbic DA neurons show different in vitro properties and synaptic inputs depending on their specific projections to the core and shell subterritories of the nucleus accumbens (NAc). However, the functional consequence of these differences is unknown. Here we analyze and model DA dynamics in different areas of the NAc to establish the real-time DA signal. In freely behaving animals, we find that the DA signal from mesencephalic neurons projecting to the NAc shell is dominated by synchronized bursts and pauses, whereas signaling is uniform for core-projecting neurons; this difference is amplified by cocaine.

\section{Introduction}

Dopamine (DA) signaling in the nucleus accumbens (NAc) plays a central role in motivation and reinforcement learning (Schultz, 2010; Salamone and Correa, 2012). However, anatomically distinct NAc subterritories, the "shell" and "core" (Groenewegen et

\footnotetext{
Received June 17, 2015; revised Nov. 8, 2015; accepted Nov. 15, 2015.

Author contributions: J.K.D. and B.J.A. designed research; J.K.D., C.M.V.W., and V.L. performed research; J.K.D., C.M.V.W., and V.L. analyzed data; J.K.D., C.M.V.W., V.L., and B.J.A. wrote the paper.

This work was supported by the Lundbeck Foundation and the University of Copenhagen 2016 Excellence Programme for Interdisciplinary Research (DSIN) to J.K.D., and the National Institute of Drug Abuse (P01 DA031656) to B.J.A.

The authors declare no competing financial interests.

Correspondence should be addressed to Dr. Jakob K. Dreyer, Department for Neuroscience and Pharmacology, University of Copenhagen, Blegdamsvej 3, 24.3.45, DK-2200 Copenhagen, Denmark. E-mail: jakobdr@sund.ku.dk.

D0I:10.1523/JNEUROSCI.2326-15.2016

Copyright $\odot 2016$ the authors $\quad 0270-6474 / 16 / 360098-15 \$ 15.00 / 0$
}

al., 1999), exert opposing influences on reward delay discounting, impulsivity, and drug taking (Pothuizen et al., 2005; Murphy et al., 2008; Dalley et al., 2011) and subpopulations of DA neurons presumably transmit different signals in these territories (Sokolowski and Salamone, 1998; Di Chiara et al., 2004; Ito and Hayen, 2011). However, resolving the real-time DA signals would require simultaneous knowledge of the synchronized activity of the specific DA projections from the ventral tegmental area (VTA), and assessment of the real-time functional effects of the cell activity on postsynaptic targets, which is a technical impossibility at the present time.

In the absence of complete data, we show that combining mathematical models of DA signaling with real in vivo data from fast-scan cyclic voltammetry (FSCV; Aragona et al., 2008; Owesson-White et al., 2009; Badrinarayan et al., 2012) predicts the functional DA signal arising from projection-specific DA 
neuron populations. Our analysis highlights several novel aspects of presynaptic and postsynaptic DA signaling. We first show that variable efficacy of presynaptic autoreceptors is the single most influential parameter for determining interstitial DA levels in the individual, such that high-efficacy results in low DA levels, and explains individual differences in pharmacologic responsiveness to psychostimulants and D2-receptor antagonists. We also predict that in freely behaving rats, interstitial DA levels in the NAc core are derived from a subset of mesolimbic DA neurons with nearly constant firing rate (Grace and Bunney, 1984b), whereas DA levels in the NAc shell result from DA neurons with highly dynamic firing pattern, including bursts and pauses (Grace and Bunney, 1984a; Paladini and Roeper, 2014). Our model predicts that intravenous (i.v.) cocaine treatment enhances the phasic signaling by the mesolimbic DA neurons projecting to the shell, while decreasing the firing rate of neurons projecting to the core.

In the classical tonic/phasic model of DA signaling, phasic DA release signals at intrasynaptic receptors, whereas extrasynaptic receptors receive DA spillover (Grace, 2000). However the view that the functional DA signal depends on submicron-scale spatial effects has been challenged by numerical estimates of diffusion rates (Cragg and Rice, 2004; Arbuthnott and Wickens, 2007), which support a temporal DA signal where D1-like and D2-like DA receptors are differentially activated by phasic deviations from some baseline DA neuron firing (Frank, 2005; Hikosaka, 2007; Gurney et al., 2015). This view is in agreement with a detailed biophysical model of DA release (Dreyer et al., 2010), which has been generalized for conditions of pharmacologic blockade of plasma membrane transporters (DATs; Dreyer and Hounsgaard, 2013) and Parkinson's disease (Dreyer, 2014). However, these biophysically constrained models also predict that DA receptors should be highly sensitive to synchronous activity in subpopulations of DA neurons. In the present study using a simplified model of the DA signal, we detect a striking pattern of differential real-time activation of DA receptors in NAc core and shell.

To gain insight into the functional consequences of these region-specific DA signals, we extended our computational model, including validation in a phantom experiment with recovery of a known input. We then investigated efficacy of presynaptic autoreceptors as a determinant of differing extracellular DA levels between individuals, and showed that our model captures real differences in dynamic firing of DA neurons projecting to NAc shell and core. Finally, we apply the model to investigate responses of firing patterns upon pharmacological challenge with cocaine.

\section{Materials and Methods}

Animals, surgery, and FSCV

Animals and surgery. Male Sprague-Dawley rats $(\sim 300 \mathrm{~g} ; N=36)$, preimplanted with jugular vein catheters, were obtained from Charles Rivers Laboratories. Rats were housed individually with ad libitum access to food and water and maintained on a $12 \mathrm{~h}$ reverse light/dark cycle (lights on at 18:00). After $\sim 5 \mathrm{~d}$ of acclimation, rats were anesthetized with ketamine hydrochloride ( $90 \mathrm{mg} / \mathrm{kg}$; i.m.) and xylazine hydrochloride (10 $\mathrm{mg} / \mathrm{kg}$; i.m.). Surgical procedures used were as previously described (Porter-Stransky et al., 2011). In brief, each rat was implanted with a guide cannula (Bioanalytical Systems) targeting coordinates relative to bregma dorsal of the left NAc core (AP $+1.3 \mathrm{~mm}, \mathrm{ML}+1.3 \mathrm{~mm}$, DV $-2.0 \mathrm{~mm}$ ) or shell (AP $+1.8 \mathrm{~mm}, \mathrm{ML}+0.8 \mathrm{~mm}, \mathrm{DV}-2.0 \mathrm{~mm})$, and an $\mathrm{Ag} / \mathrm{AgCl}$ reference electrode in the contralateral cortex (AP $-0.4 \mathrm{~mm}$, $\mathrm{ML}-4.0 \mathrm{~mm}, \mathrm{DV}-4.0 \mathrm{~mm}$ ). A bipolar stimulating electrode (Plastics One) was secured in the VTA (AP $-5.2 \mathrm{~mm}, \mathrm{ML}+0.8 \mathrm{~mm}, \mathrm{DV}-7.5$ to $-8.0 \mathrm{~mm}$ ), the position where we obtained maximal stimulated release under anesthesia $(60 \mathrm{~Hz}, 60 \mathrm{p}, 120 \mu \mathrm{A})$. Implants were secured to the skull with four surgical screws and dental acrylic. The University of Michigan Committee on Animal Use and Care approved all procedures and experiments.

$F S C V$. Following postoperative recovery for a week, rats were exposed to the testing chamber for $\sim 2 \mathrm{~h}$ the day before commencing the pharmacology experiment. A recording cable, suspended from a rotating commutator (Crist Instruments) above the recording chamber, was secured with contact to the rat's stimulating electrode, and polyethylene tubing loaded with saline vehicle was secured to the jugular vein catheter, and connected to a syringe pump outside the chamber. An epoxied carbon-fiber microelectrode (Exposed fiber length $\sim 120 \mu \mathrm{m}$ ) was lowered into the NAc core (DV $=-6.6 \mathrm{~mm}$ from brain surface) or shell $(\mathrm{DV}=-5.7 \mathrm{~mm}$ from brain surface) and locked into position. We observed both naturally occurring DA release events (DA "transients") and electrically stimulated DA release (60 Hz: 24 pulses, 12 pulses, 6 pulses; $30 \mathrm{~Hz}$ : 24 pulses, 12 pulses, 6 pulses; $20 \mathrm{~Hz}, 4$ pulses; $120 \mu \mathrm{A}$ ). FSCV recordings were collected at $10 \mathrm{~Hz}$ by applying a triangular potential $(-0.4$ to $+1.3 \mathrm{~V}$, and back to $-0.4 \mathrm{~V})$. For a detailed explanation of waveform parameters and signal analysis, see Robinson et al. (2003) and Wightman et al. (2007).

As in a previous FSCV pharmacological experiment (Vander Weele et al., 2014), we assessed DA during four distinct $15 \mathrm{~min}$ recording periods: (1) baseline, and following intravenous infusions of (2) saline, (3) cocaine $\mathrm{HCl}$ (Sigma-Aldrich; $3.0 \mathrm{mg} / \mathrm{kg}$ ), and (4) raclopride $\mathrm{HCl}$ (SigmaAldrich; $1 \mathrm{mg} / \mathrm{kg}$ ). All intravenous solutions were delivered as $0.2 \mathrm{ml}$ boluses, initiated $30 \mathrm{~s}$ into the recording period. Recording during electrical stimulation of the VTA $(60 \mathrm{~Hz}, 24$ pulses, $120 \mu \mathrm{A})$ after each $15 \mathrm{~min}$ recording period was used to verify electrode quality. After in vivo recordings, electrodes were calibrated by immersion in $1 \mu \mathrm{M}$ DA solution; current changes were converted to DA concentration using principle component regression, relative to earlier recordings of DA release and pH changes obtained with a training set (Heien et al., 2005; Keithley et al., 2009; Keithley and Wightman, 2011).

Upon completion of the experiment, rats were euthanized with ketamine hydrochloride $(0.2 \mathrm{ml}, 10 \mathrm{mg} / \mathrm{ml}$, i.v $)$, and an electrolytic lesion was made with a tungsten electrode to mark the recording sites, followed by removal and postfixation of brains in $4 \%$ formalin. To verify electrode placement, coronal brain slices were cut on a cryostat, mounted, and stained with cresyl violet before microscopic examination.

\section{Theoretical analysis of dynamic DA levels}

We assume that the FSCV measurement to reflect the action potentialdependent DA release from neuronal activity of a population of VTA DA neurons with terminals near the recording site. We furthermore assume the DA concentration, $C$, to be described by the nonlinear differential equation:

$$
\frac{d}{d t} C=\gamma(t) \cdot \nu(t)-\frac{V_{\max } C(t)}{K_{M}+C(t)} .
$$

Here, the left-hand side describes the time derivative of the DA concentration. The first term on the right-hand side denotes DA release, described as the product of two time-dependent factors: $\gamma(t)$, the release capacity, and $\nu(t)$, the group mean firing rate of the relevant VTA neuronal population. The second term on the right-hand side describes DA uptake in terms of $V_{\max }$, the maximal uptake capacity, and $K_{\mathrm{m}}$, the Michaelis-Menten constant, fixed to $0.16 \mu \mathrm{M}$ (John and Jones, 2007). The value of $\gamma(t)$ corresponds to the incremental increase in extracellular DA concentration by a single synchronized action potential at time $t$. The release capacity is given as follows (Dreyer et al., 2010):

$$
\gamma(t)=P_{r}(t) \frac{N_{0} \rho_{s}}{\alpha_{\text {e.s. }} N_{A}}=P_{r}(t) \frac{\gamma_{p}}{\mathrm{P}_{p}},
$$

where $P_{\mathrm{r}}(t)$ is autoreceptor-dependent vesicular release probability, $N_{0}$ is the number of DA molecules released per vesicle fusion, $\rho_{s}$ is the volume density of release sites, $\alpha_{\text {e.s. }}$ is the volume fraction of extracellular space, and $N_{A}$ is Avogadro's number. In the model developed here, the release capacity $P_{\mathrm{r}}(t)$ is regulated by presynaptic DA autoreceptors and changes 
with DA release and pharmacological manipulations, whereas the other parameters in Equation 2 are assumed to be constant. The release capacity from electrically evoked release is $\gamma_{\mathrm{p}}$ (see Eq. 13) and the corresponding release probability is denoted as $P_{\mathrm{p}}$ (see Eq. 8). The relationship between DA cell firing rate, presynaptic autoreceptors and release probability is further described below.

Equation 1 is a generalization of earlier models used to analyze artificially evoked DA transients in vivo or in ex vivo (Wightman and Zimmerman, 1990). Here, we aim to develop a universal model applicable to all aspects of the DA signal, including naturally occurring transients and tonic DA release. Because of the nonlinear nature of Equation 1, it is only valid when $C$ indicates the real, absolute DA concentration, whereas our FCSV recordings provide only a relative measure of DA dynamics. For any self-consistent model, the prevailing DA level must be related to the average firing rate of the of the DA neurons. An essential step in our analysis is therefore to infer the absolute concentration of DA by assuming a value in $\mathrm{Hz}$ for the long-term average firing rate.

In FSCV recordings, we used electrically evoked transients to determine two constants $V_{\max }$ and $\gamma_{\mathrm{p}}$ (see below), where $\gamma_{\mathrm{p}}$ is assumed to be close to the time average of $\gamma(t)$. For a constant firing rate, $\nu_{0}$, where $\nu_{0}<$ $V_{\text {max }} / \gamma_{\mathrm{p}}$, the steady-state DA level $C_{\nu_{0}}$ is given by the following:

$$
C_{\nu_{0}}=\frac{K_{m} \nu_{0} \gamma_{p}}{V_{\max }-\nu_{0} \gamma_{p}} \text {. }
$$

The subscript serves as a reminder that $C_{\nu_{0}}$ depends on the firing rate $\nu_{0}$. We assume that the relevant VTA neurons have long-term average firing rate $\nu_{0}=4 \mathrm{~Hz}$ (Hyland et al., 2002), and then use Equation 3 as an approximation of the average DA level, denoted as $C_{4 \mathrm{~Hz}}$.

Before analysis of FSCV time-series recorded under baseline and saline infusion conditions, we first subtracted any linear trend in the FSCV data, and then defined,

$$
C(t)=C_{\mathrm{FSCV}}(t)+C_{4 \mathrm{~Hz}}-\left\langle C_{\mathrm{FSCV}}(t)\right\rangle,
$$

where $C_{\mathrm{FSCV}}(t)$ is a calibrated FSCV recording (with removed linear trend) and $\left\langle C_{\mathrm{fcsv}}(t)\right\rangle$ is the mean value of the FSCV signal. The resulting time series $C(t)$ is a model-dependent approximation of the actual DA level at the recording site. Ideally, negative values should not occur in $C(t)$, but can arise due to statistical noise in the FSCV recording and because of small deviations between $C_{4 \mathrm{~Hz}}$ and the true average DA. We estimate DA release rate from Equation 1 using the following:

$$
\gamma(t) \nu(t)=\frac{d C}{d t}+\frac{V_{m} C(t)}{K_{M}+C^{*}(t)} .
$$

Here $C^{*}(t)=C(t)$ whenever $C(t)>0$, and 0 otherwise. The right-handside of Equation 5 is used in combination with Equation 2 to determine the firing rate $\nu(t)$ in $\mathrm{Hz}$, which represents the mean firing rate needed to reestablish the absolute DA level under Equation 1; because the average DA concentration is calculated assuming $\nu_{0}=4 \mathrm{~Hz}$, the average firing rate will lie close to this.

\section{Presynaptic autoreceptor control of vesicular release probability}

Direct experimental determination of the in vivo vesicular release probability is not available, although in vitro studies and numerical arguments suggest that DA release is dominated by failures (Wallace and Hughes, 2008; Dreyer et al., 2010; Pan and Ryan, 2012). We assumed that $P_{r}(t)$ is controlled by occupancy of presynaptic D2-like autoreceptors [D2 $\left.{ }^{\mathrm{pre}}(t)\right]$ by DA. The $\mathrm{D} 2^{\text {pre }}$ occupancy is calculated dynamically from the DA concentration using on- and off-rates described by Dreyer and Hounsgaard, 2013, and takes values ranging between 0 and 1. From the occupancy we calculated the following:

$$
P_{r}(t)=\frac{P_{\max }}{1+\beta \mathrm{D} 2^{\mathrm{pre}}(t)},
$$

where $P_{\max }=12 \%$ is the maximal allowed release probability and $\beta$ is a control parameter determining the autoreceptor efficacy. We then let the following:

$$
\mathrm{D} 2_{4 \mathrm{~Hz}}^{\mathrm{pre}}=\frac{C_{4 \mathrm{~Hz}}}{\mathrm{EC}_{50}^{\mathrm{pre}}+C_{4 \mathrm{~Hz}}},
$$

denote steady-state activation of $\mathrm{D} 2{ }^{\text {pre }}$ at $4 \mathrm{~Hz}$ tonic cell firing, and use $\mathrm{EC}_{50}^{\mathrm{pre}}=0.040 \mu \mathrm{M}$ (Dreyer and Hounsgaard, 2013).

\section{Determining efficacy of presynaptic autoreceptors from experimental data}

The autoreceptor efficacy, $\beta$, is a key parameter in this study. Across the population we observe an overall linear relationship between $\gamma_{\mathrm{p}}$ and $V_{\max }$ during evoked release, with $\alpha=0.0602 \mathrm{~s}$ as constant of proportionality (see Fig. $4 A$, red dashed line). Thus on average one expects that $\gamma_{\mathrm{p}} /$ $V_{\max }=\alpha$. However, in individual animals, the measured ratio, $\gamma_{\mathrm{p}} / V_{\max }$ deviates slightly from the group mean. This deviation leads to different predictions of average DA concentrations across the population, which we use to determine autoreceptor efficacy. We first define the following:

$$
P_{p}=P_{0} \frac{\gamma_{p}}{\alpha V_{\max }}
$$

where $P_{0}=2 / 3 P_{\max }$ (ie, $8 \%$ ) is the release probability under tonic firing for individual rats in which $\gamma_{\mathrm{p}}=\alpha V_{\max }$. We then estimated $\beta$ directly from measured data as follows:

$$
\beta=\frac{P_{\max }-P_{p}}{P_{p} \mathrm{D} 2_{4 \mathrm{~Hz}}^{\mathrm{pre}}}=\left(\alpha \frac{V_{\max } P_{\max }}{\gamma_{p} P_{0}}-1\right)\left[\frac{\mathrm{EC}_{50}^{\mathrm{pre}}\left(\frac{V_{\max }}{\gamma_{p}}-\nu_{0}\right)}{K_{M} \nu_{0}}+1\right]
$$

The most critical parameters in this estimate model are the ratios $P_{\max } / P_{0}$ and $V_{\max } / \gamma_{\mathrm{p}}$ (Eq. 9). The determination of autoreceptor control is consequently robust against uncertainty in absolute release probability and calibration of the carbon-fiber FSCV recording electrode.

Low DA levels (observed when $\gamma_{\mathrm{p}}<\alpha V_{\max }$ ) lead to high value of $\beta$, whereas high DA levels (observed when $\gamma_{\mathrm{p}}>\alpha V_{\text {max }}$ ) lead to low autoreceptor efficacy. Therefore, our theory predicts a negative correlation between $C_{4 \mathrm{~Hz}}$ and the increase in DA release if autoreceptors are blocked. Experimentally we test this prediction by measuring the ratio of DA release before and after blockade of autoreceptors using the D2/3 antagonist raclopride and compare this to the preinfusion value of $C_{4 \mathrm{~Hz}}$.

\section{Estimation of postsynaptic activation}

Postsynaptic D1-like and D2-like receptors are found in both high- and low-affinity states (Richfield et al., 1989). Because the proportions of receptors in the biologically relevant high-affinity state remains controversial (Cumming, 2011; Skinbjerg et al., 2012; Marcott et al., 2014), we estimated the functional postsynaptic effects by different methods. We first determined binding to both high- and low-affinity state receptors. We then used the low-affinity state binding to assess D1- and D2regulated activation of postsynaptic cascades (Dreyer, 2014).

We used quasi-stationary Michaelis-Menten model to estimate binding to high-affinity $\left(R^{\text {high }}, K \mathrm{~d}=0.01 \mu \mathrm{M}\right)$ and low-affinity targets $\left(R^{\text {low }}\right.$, $K \mathrm{~d}=1 \mu \mathrm{M}$; Dreyer et al., 2010). Models of D1 or D2 regulated postsynaptic signals were implemented as follows (Dreyer, 2014):

$$
\text { D1-activation }=\left\{\begin{array}{cl}
\frac{1}{\gamma_{p}}\left(\mathrm{R}^{\text {low }}(t)-\mathrm{R}_{4 \mathrm{~Hz}}^{\text {low }}\right) & \text { for } \mathrm{R}^{\text {low }}(t) \geq \mathrm{R}_{4 \mathrm{~Hz}}^{\text {low }} \\
0 & \text { for } \mathrm{R}^{\text {low }}(t)<\mathrm{R}_{4 \mathrm{~Hz}}^{\text {low }}
\end{array}\right.
$$

and

$$
\text { D2-activation }=\left\{\begin{array}{cl}
0 & \text { for } \mathrm{R}^{\text {low }}(t) \geq \mathrm{R}_{4 \mathrm{~Hz}}^{\text {low }} \\
\frac{1}{\gamma_{p}}\left(\mathrm{R}_{4 \mathrm{~Hz}}^{\text {low }}-\mathrm{R}^{\text {low }}(t)\right) & \text { for } \mathrm{R}^{\text {low }}(t)<\mathrm{R}_{4 \mathrm{~Hz}}^{\text {low }}
\end{array}\right.
$$


A
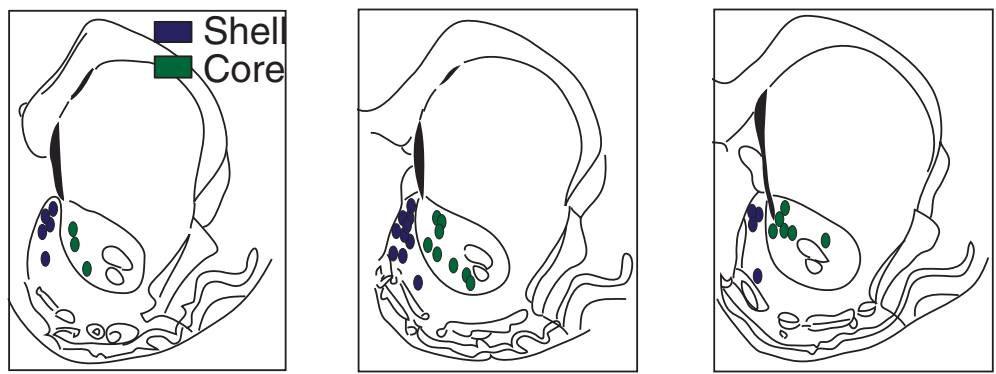

B
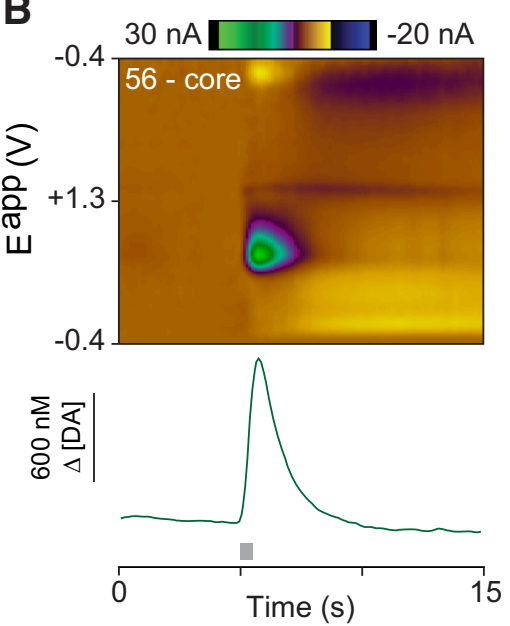

$-0.4$
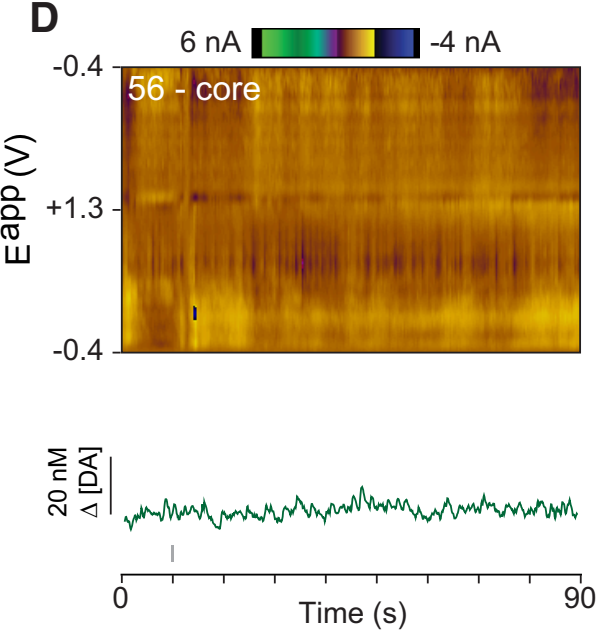

E
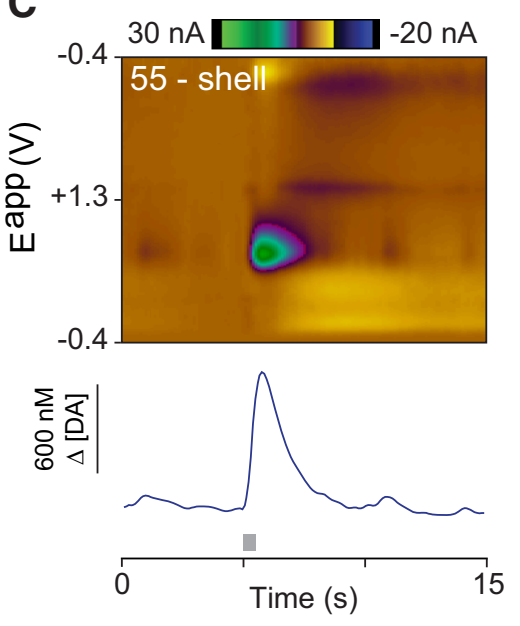

Figure 1. Overview of FSCV data. A, Anatomical locations within NAc for FSCV recordings. Each rat was implanted with one recording electrode. $\boldsymbol{B}$, Electrically evoked DA transient in NAc core. Top, Voltammogram; bottom, DA transient from electrically evoked release. Gray bar at $t=5$ indicates stimulus train (24 pulses at $60 \mathrm{~Hz}$ ). C, Electrically evoked DA transient in NAc shell. $D$ Spontaneous DA in NAc core with intravenous saline infusion. Top, Voltammogram; bottom, DA concentrations. Gray bar at $t=$ 10 s indicates infusion. $\boldsymbol{E}$, Spontaneous DA in NAc shell during intravenous saline infusion.

Here $R^{\text {low }}(t)$ is occupancy of a low-affinity DA receptor at time $t$ and $\mathrm{R}_{4 \mathrm{~Hz}}^{\text {low }}$ is low-affinity receptor binding $<4 \mathrm{~Hz}$ tonic cell firing. Note that D1regulated activation occurs when $C(t)$ is $>4 \mathrm{~Hz}$ baseline, and that D2regulated activation occurs when $C(t)$ is $>4 \mathrm{~Hz}$ baseline. We also calculated D2-regulated signaling assuming high-affinity receptor binding, $R^{\text {high }}(t)$, with similar results. Normalizing postsynaptic signaling the gain by $\frac{1}{\gamma_{p}}$ and activation threshold by $\mathrm{R}_{4 \mathrm{~Hz}}^{\text {low }}$ ensures that the postsynaptic signals are consistent between different animals, even if their tonic and phasic DA levels differ.

\section{Experimental determination of release} and uptake constants

We used evoked DA release to determine release and uptake constants for each recording. Here, $V_{\max }$ was estimated from the maximal clearance rate after evoked release after VTA stimulation (12-24 pulses at $60 \mathrm{~Hz})$, and $\gamma_{\mathrm{p}}$ from the maximal rate of DA appearance in the FCSV transients (Wu et al., 2001). We measured these directly on FSCV recorded transients and defined the following:

$$
V_{\max }=\frac{\Delta C\left(t_{\min }\right)}{\Delta t} \frac{K_{m}+\tilde{C}\left(t_{\min }\right)}{\tilde{C}\left(t_{\min }\right)},
$$

where $\tilde{C}(t)=C_{\mathrm{FSCV}}(t)-\min \left(C_{\mathrm{FSCV}}(t)\right)$, and where $C_{\mathrm{FSCV}}$ is from the FSCV recording, with removed mean and linear trend, and $t_{\min }$ is the time point where the rate of decay, $\frac{\Delta C}{\Delta t}$, is maximal (see Fig. 3B1,B2, green). The second factor in Equation 12 is a correction for the finite level of DA at $t_{\min }$. The derivative $\frac{\Delta C}{\Delta t}$, was determined from the difference between consecutive data points.

Similarly we determined $\gamma_{\mathrm{p}}$ from the maximal rate of DA appearance during the stimulus train, and defined the following:

$$
\gamma_{p}=\nu_{\text {stim }}^{-1}\left(\frac{\Delta C\left(t_{\max }\right)}{\Delta t}+V_{\max }\right),
$$

where $t_{\max }$ is the time point where the rate of appearance, $\frac{\Delta C}{\Delta t}$, is maximal (see Fig. 3B1,B2, red). Our method of obtaining $\gamma_{\mathrm{p}}$ contains a correction term for the maximal possible DA uptake during the stimulus train; the corrections in Equations 12 and 13 ensure values of $V_{\max }$ and $\gamma_{\mathrm{p}}$ slightly higher than the maximal rates of appearance and disappearance of the evoked DA transient.

DA release was also measured after infusion of $1.0 \mathrm{mg} / \mathrm{kg}$ raclopride (i.v.). In our hands, transients recorded after raclopride infusion were longer, apparently indicating reduced uptake capacity. However, in simulations of autoreceptor blockade we also observed apparently reduced uptake even though $V_{\max }$ was unaltered (see Fig. 4D, left); the apparent reduction of $V_{\max }$ in simulations was due to competition with increased extracellular DA (Dreyer et al., 2010). We therefore only determined DA release, $\gamma_{p}^{\mathrm{rac}}$, using the method above and using preinfusion value of $V_{\max }$. The raclopride dataset include observations where a cocaine or opioid (morphine or oxycodone) infusion was administered between pre- and postraclopride measurements (Aragona et al., 2008; Vander Weele et al., 2014), but preinfusion values were always determined from transients recorded before any administration of active drugs.

\section{D diffusion model of DA detection with carbon fiber}

For validation of our method we first applied our analysis in a simulated experiment. Here we implemented the 3D diffusion model as described by Dreyer and Hounsgaard (2013), which includes effects of terminal and somatodendritic DA autoreceptors. For accurate depiction of an FSCV measurement, we added a simulated carbon-fiber FSCV probe to the 43 
$\mu \mathrm{m}$ simulation space. The carbon fiber was modeled as a square rod measuring $6 \mu \mathrm{m}$ transecting the simulation volume (see Fig. $3 A$ ). The rod had a reflecting boundary condition, and a $2 \mu \mathrm{m}$ dead layer around the electrode (Schmitz et al., 2003). DA terminals in the dead layer were restricted from releasing DA, but allowed to contribute to uptake. Volume fraction and tortuosity in the dead layer were the same as in the bulk tissue. Simulated FSCV data were estimated as the mean extracellular DA level in the vicinity of the probe sampled at $10 \mathrm{~Hz}$, as in FSCV experiments. Note that because of periodic boundary conditions in the simulations, the simulated FSCV experiments represent the idealized situation of an infinitely long recording electrode, embedded in homogeneously distributed DA release sites.

The phantom experiment consisted of two simulations. In one we used an emulation of stimulated release $(24$ pulses at $60 \mathrm{~Hz}$ ) for determination of $\gamma_{\mathrm{p}}$ and $V_{\max }$ by Equations 12 and 13 and to use these to calculate $C_{4 \mathrm{~Hz}}$. Here, prestimulus and poststimulus DA levels were defined by a $4 \mathrm{~Hz}$ tonic firing pattern. In a second set of simulations, we simulated spontaneously fluctuating DA levels resulting from a phasic firing pattern, so as to evaluate the accuracy of the baseline approximation. Here, the average VTA neuron firing rate was set to 3,4 , or $5 \mathrm{~Hz}$, but with a significant degree of bursts and pauses. 3D simulations without carbon fiber probe were used to simulate DA levels under intravenous cocaine, with DA levels reported as the volume average DA concentration in the simulation volume.

\section{Statistical analysis}

We used propagation of errors to determine the influence of the uncertainty in $V_{\max }, \gamma_{\mathrm{p}}$, and $\nu_{0}$ on $C_{4 \mathrm{~Hz}}$. In the error analysis, we accounted for the covariance between $V_{\max }$ and $\gamma_{\mathrm{p}}$ introduced by Equation 13, and assumed a SE of $1 \mathrm{~Hz}$ in average firing rate. We used the Student's $t$ test to compare values of $C_{4 \mathrm{~Hz}}$ and the experimentally obtained $V_{\max }$, and $\gamma_{\mathrm{p}}$ between NAc core and shell. The correlations between $C_{4 \mathrm{~Hz}}$ and $V_{\max }$, and between $\gamma_{p}$, and the fraction $\gamma_{p}^{\text {rac }} / \gamma_{p}$ were tested using Pearson's linear correlation coefficient. The uncertainty in the estimate $\gamma_{p}^{\text {rac }} / \gamma_{p}$ was determined using SEM of $\gamma_{p}^{\text {rac }}$ and $\gamma_{p}$ in conjunction with propagation of errors.

We used the MATLAB function "gmdistribution" to check for multiple modalities on predicted firing rate. Here a trimodal distribution was fitted to the collection of firing rates recorded from animals in baseline and saline recordings, which gave a better fit to NAc shell data than did unimodal or bimodal distributions according to the Akaike Information Criterion. Simulations and analysis was performed in MATLAB R2012b.

\section{Results}

In the present study, we combine FSCV recordings in freely moving rats and a novel mathematical model of DA kinetics. We use FSCV data to predict DA levels, feedback by presynaptic terminal autoreceptors, firing patterns of the relevant subset of DA neurons projecting to the recording site, and postsynaptic effects thereof. We also compare our model to simulated experiments. Here DA concentrations are calculated from first principles using a detailed model that includes distinct release sites, the physical presence of the probe, and feedback from somatodendritic and presynaptic autoreceptors.

\section{Different spontaneous DA signals in NAc shell and NAc core}

In each rat, a carbon fiber recording electrode was placed in either NAc core or shell (Fig. 1A), to detect time-varying DA concentrations with a time resolution of $0.1 \mathrm{~s}$. The presence of DA release near the probe was determined by evoking DA transients by electrical stimulation of VTA cell bodies (Fig. $1 B$, core, $C$, shell). Previous studies have shown that even in the presence of electrically releasable DA, the amplitude of spontaneously occurring DA transients is heterogeneous in NAc (Wightman et al., 2007). To test whether we could reproduce this heterogeneity, we analyzed spontaneous DA fluctuations recorded while freely moving rats were exploring the test chamber (Fig. 1D, NAc core, and E,

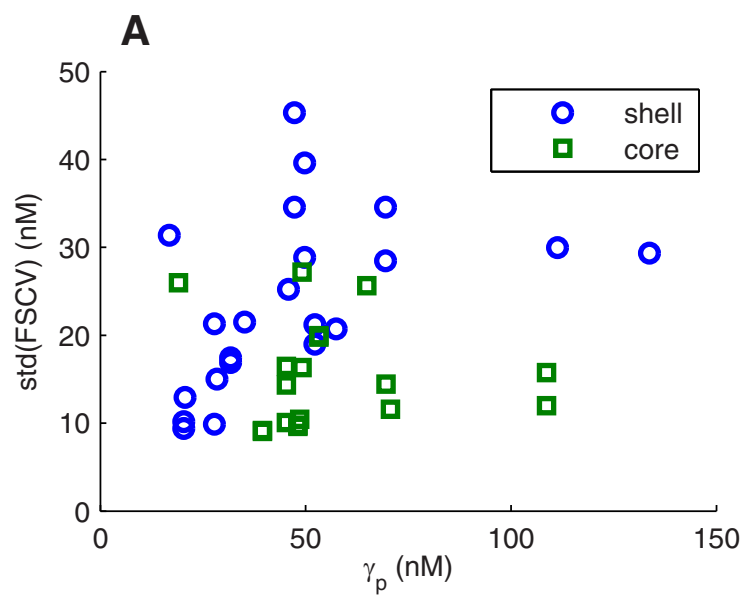

B

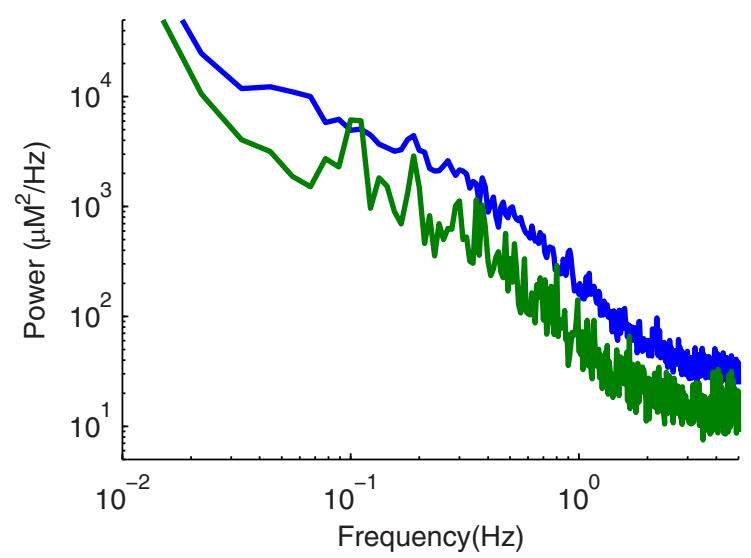

Figure 2. Comparison of variability in FSCV recordings in NAc core and shell. $A$, SD of FSCV time series as function of maximal rate of electrically evoked DA release. Each marker represents a single animal. Blue, NAc shell; green, NAc core. B, Power spectrum of FSCV recordings. Blue, NAc shell; green, NAc core.

NAc shell). We observed differing patterns of variability in NAc core and shell. Even though the electrically evoked DA transients could have similar mean amplitude, the SD of the spontaneous DA transients was almost always higher in NAc shell than in core (Fig. 2A). When the FSCV variability was normalized to the rate of evoked DA release $\left(\gamma_{p}\right)$, we found a statistically significant difference between recordings in NAc core and shell $(p=0.01)$. Furthermore, power spectral analysis of the recordings showed that the variability in NAc shell was higher across most non-zero frequencies (Fig. 2B). Thus, the amplitudes both of fast transients and relatively slow oscillations were higher in NAc shell than in core. This indicates that the increased variability detected in NAc shell most likely is a signature of regionally specific neuronal activity of inputs from the VTA.

However, qualitative analysis of FSCV transients does not in itself reveal the functional consequences of these differences in the DA signal. For example, is the variability linked to the different roles of NAc core and shell in motivation? Does it reflect a particular aspect of particular firing patterns of VTA neurons? We now develop a mathematical framework to link DA fluctuations with a functionally relevant DA signal, in a model including activation of presynaptic and postsynaptic DA receptors. From the electrically evoked transients, we extracted physiological parameters describing DA release $\left(\gamma_{\mathrm{p}}\right)$ and uptake $\left(V_{\max }\right)$ at the recording site. In turn, from these parameters we tailored a math- 
A

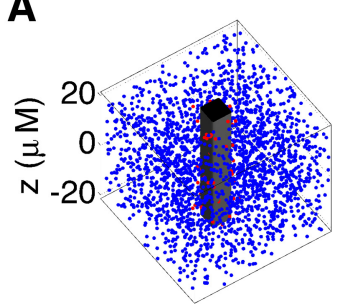

B1
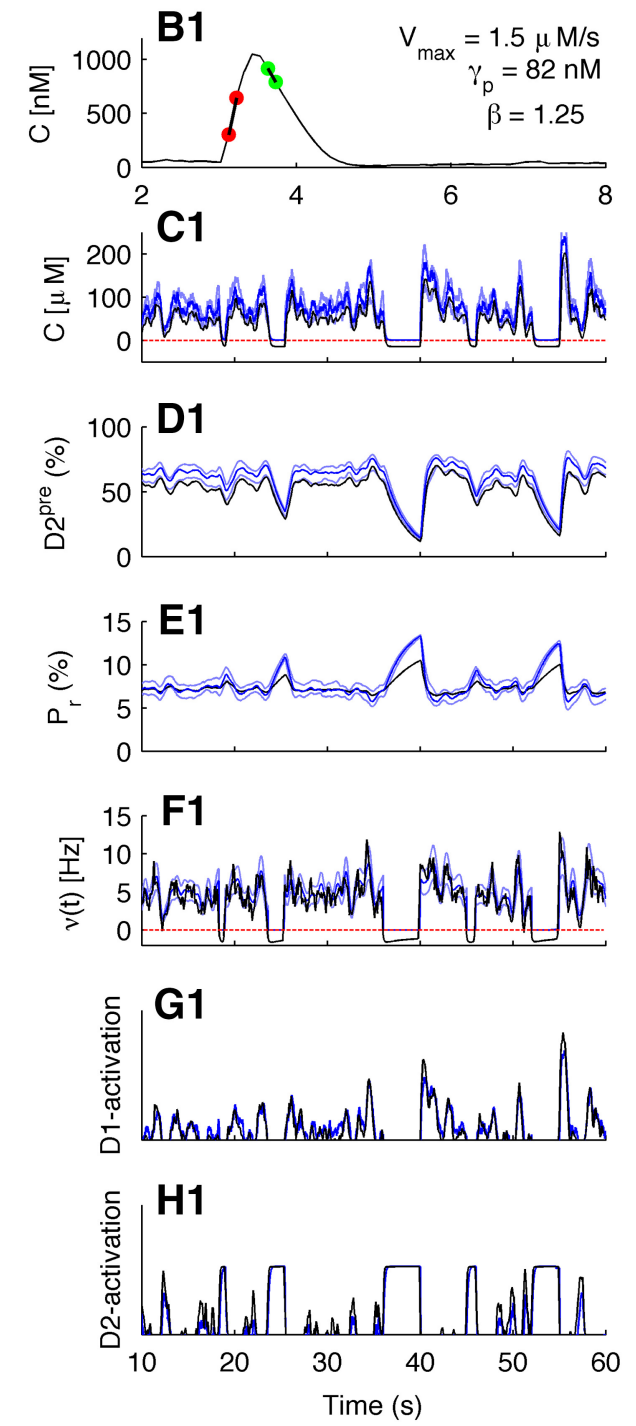
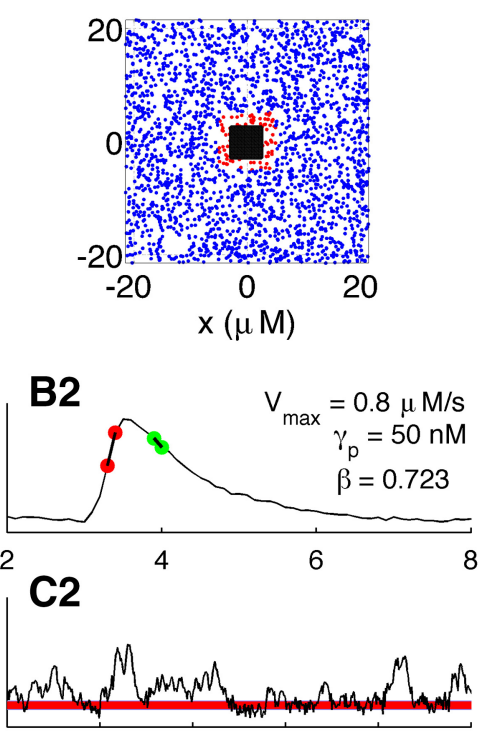

D2

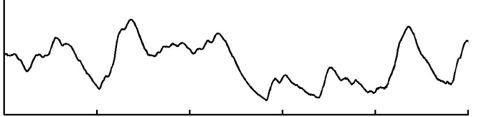

\section{E2}

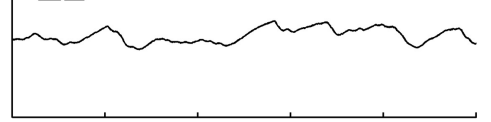

F2

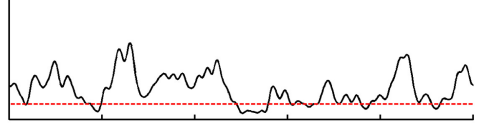

G2

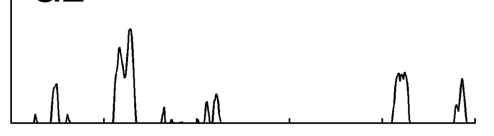

H2

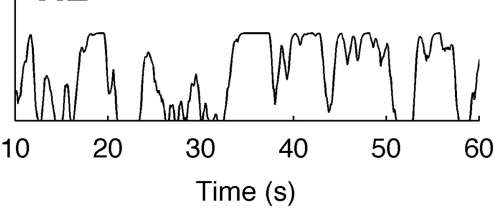

Figure 3. Application of model to phantom experiment and comparison with FSCV example. $\boldsymbol{A}$, Geometry of simulated experiment. Left, Side view of simulation space (width $43 \mu \mathrm{m}$ ). Right: Top view of simulation space. Black area indicates carbon fiber, blue dots are DA release and re-uptake sites, red dots are sites with DA uptake only lying in the dead volume defined within $2 \mu \mathrm{m}$ from the probe surface. $\boldsymbol{B 1}-\boldsymbol{F 1}$, Results from analysis of simulated data. Dark blue indicate results from simulation at $4 \mathrm{~Hz}$ average firing rate of VTA neurons. Light blue indicates results from simulation at $3 \mathrm{~Hz}$ or $5 \mathrm{~Hz}$ average firing. Black shows estimates of simulation results based on $\gamma_{\mathrm{p}}$ and $V_{\text {max }}$ recovered from transients. $\boldsymbol{B 2}-\boldsymbol{F 2}$, Results from same analysis on FSCV recorded data. $\boldsymbol{B}$, Evoked transient in simulated experiment, red markers indicate the most rapid DA appearance, which is used for determination of $\gamma_{p}$ (Eq. 13). Green markers indicate fastest DA removal, which is used for determination of $V_{\max }$ (Eq. 12). Inset, Key parameters obtained from the transient. B2, Electrically evoked transient recorded with FSCV. Inset, Average of key parameters from $N=8$ transients. C1, DA concentration calculated in simulation based on $\mathrm{C}_{4 \mathrm{~Hz}}$ estimate (black) and "real" DA concentration in the simulation (blue). Red dashed line indicates 0 nm. C2, Estimated DA concentration for FSCV recording based on $C_{4 \mathrm{~Hz}}$ (black). Red line indicates $0 \mathrm{~nm}$; width indicates statistical uncertainty. D1, Estimated presynaptic D2 autoreceptor activation (black) and real value from simulation (blue). D2, estimated D2 autoreceptor activation in FSCV recording. E1, Estimated DA release probability (black), real value from simulation (blue). E2, Estimated release probability in FSCV experiment. F1, Estimated VTA neuron firing rate from simulation (black) and real firing rate in simulation (blue). F2, Estimated firing rate from FSCV experiment. G1, D1-regulated

ematical model deriving the absolute DA signal at the recording site, DA firing patterns, with terms for feedback by presynaptic DA autoreceptors, and the predicted activation of postsynaptic D1 and D2 receptors at the recording site.

\section{DA signals can be reconstructed from} transients in simulated experiment We first assessed the accuracy of our method to recover known input parameters and DA levels in a simulated FSCV recording (Fig. 3A). Here, DA levels were calculated from first principles including vesicular release, diffusion in extracellular space, and spatially heterogeneous DA uptake specifically located near DA release sites (Fig. $3 A$, blue dots). The simulation included a dual autoreceptor system in which firing rate is controlled by somatodendritic autoreceptors, and vesicular release by and presynaptic terminal autoreceptors (Dreyer and Hounsgaard, 2013).

DA release, uptake, and extracellular DA concentrations are known quantities in the simulation (Table 1), which were to be calculated only from information in the transients, using the same method as for actual in vivo recordings. We therefore simulated electrically evoked DA release by transiently increasing the firing rate of DA neurons from 4 to $60 \mathrm{~Hz}$ for a period $0.4 \mathrm{~s}$ (giving 24 spikes on average). Before the stimulus onset, the average concentration of DA at the electrode was $59 \mathrm{nM}$, and stimulus led to a 1 $\mu \mathrm{M}$ DA transient (Fig. 3B1).

In this simulation, the estimate of $V_{\max }$ was very close to the input value, whereas $\gamma_{\mathrm{p}}$ was slightly lower than the input (Table $1)$. Calculating the DA concentration from $\gamma_{p}$ and $V_{\max }$ requires knowledge of the average firing rate. When combined with a $4 \mathrm{~Hz}$ average firing rate, the estimated average DA level was $45 \mathrm{~nm}$ $\left(C_{4 \mathrm{~Hz}}\right.$; Eq. 3$)$; slightly less than the true average in the simulation. In our subsequent analyses, we use this value as an approximation of the true average baseline DA concentration.

We then simulated a baseline FSCV recording where DA levels result from a phasic DA firing pattern, including phasic bursts and pauses (Fig. 3C1, black). The firing rate was set to fluctuate in a physio-

activation. Value from simulation (blue), estimated using model (black). G2, Predicted D1-regulated activation for experiment. $\boldsymbol{H 1}, \mathrm{D} 2$-regulated activation. Value from simulation (blue), estimated using model (black). H2, Predictions of D2regulated activation for experiment. 
Table 1. Recovery of known parameters from simulation and comparison with example of same analysis applied to experimentally recorded transient using FSCV

\begin{tabular}{lcll}
\hline & $\begin{array}{l}\text { Real value in } \\
\text { simulation } \\
\text { (Fig. 3A,B1-F7) }\end{array}$ & $\begin{array}{l}\text { Determined from } \\
\text { simulated transient } \\
\text { (Fig. 3B1-F7) }\end{array}$ & $\begin{array}{l}\text { FSCV example } \\
\text { (Fig. 3B2-F2) }\end{array}$ \\
\hline Parameter & $1.53 \mu \mathrm{m} / \mathrm{s}$ & $1.50 \mu \mathrm{m} / \mathrm{s}$ & $0.90 \pm 0.06 \mu \mathrm{m} / \mathrm{s}$ \\
$V_{\text {max }}$ (Eq. 12) & $100 \mathrm{nM}$ & $82 \mathrm{nM}$ & $52 \pm 5 \mathrm{nM}$ \\
$\gamma_{\mathrm{p}}$ (Eq. 13) & $59 \mathrm{nM}$ & $45 \mathrm{~nm}$ & $48 \pm 9 \mathrm{nM}$ \\
$C_{4 \mathrm{~Hz}}$ (Eq. 3) & $\sim 1.5$ & 1.25 & 1.02 \\
$\beta$ &
\end{tabular}

Analysis of the simulation experiment and the experimental example shown in Figure 3 . Note that $\beta$ is not precisely defined in the simulation where autoreceptor activation is implemented as by Dreyer and Hounsgaard (2013).

logically plausible range between 0 and $20 \mathrm{~Hz}$, but the time average was fixed close to $4 \mathrm{~Hz}$. The model predicted DA levels were slightly lower than the true input value, which was particularly visible during pauses in cell firing (Fig. 3C1, blue). Thus, even under ideal conditions of a phantom experiment, DA release may be slightly underestimated by our method. In the phantom experiment, the difference was mainly caused by $\gamma_{\mathrm{p}}$ being $\sim 20 \%$ underestimated, this being due to dynamic activation of autoreceptors during evoked release. We expect similar autoreceptor dynamics to occur experimentally, predicting that true DA levels in vivo may likewise be slightly underestimated by our method.

In theory, models that include the effect of tonic DA firing and dynamic activation of autoreceptors can give more accurate estimate of the input parameters. However, in this case, the parameters to be determined will influence the premises used to determine them. This reduces the robustness of more advanced methods, whereas the current method is stable and more transparent. Another uncertainty is that the true firing rate of the assemblage of specific DA neurons projecting to the recording site is not precisely known in experimental recordings. To test the influence of this uncertainty, we altered the mean firing rate in the phantom simulation. When the overall firing rate was reduced to $3 \mathrm{~Hz}$, the mean extracellular DA concentration fell to 44 $\mathrm{nM}$ and when firing rate was increased to $5 \mathrm{~Hz}$, the DA increased to $72 \mathrm{~nm}$ (as mentioned above, the true mean DA level was $59 \mathrm{~nm}$ when firing rate was $4 \mathrm{~Hz}$ ). Thus a $\pm 1 \mathrm{~Hz}$ deviation between the real firing rate and the $4 \mathrm{~Hz}$ input in the analysis will add $\sim 25 \%$ uncertainty in the DA level (Fig. 3C1). Even though this uncertainty was carried into estimates of terminal DA release probability and firing rate, the recovered data were still qualitatively descriptive (Fig. 3D1-F1).

We compared the uncertainty in the simulation results to the statistical uncertainty in experimental parameters obtained from eight transients recorded in a single animal; $V_{\max }=0.90 \pm 0.06 \mu \mathrm{M} / \mathrm{s}$ and $\gamma_{\mathrm{p}}=52 \pm 5 \mathrm{~nm}$ (Table 1; Fig. $3 B 2$ shows a single transient). Correspondingly the average DA level, $C_{4 \mathrm{~Hz}}$, is $\sim 48 \pm 9 \mathrm{nM}$ (here, the SEM is obtained using propagation of errors and includes the $\pm 1 \mathrm{~Hz}$ uncertainty in tonic firing rate discussed above). We then analyzed recordings of spontaneous activity using $C_{4 \mathrm{~Hz}}$ as the average (Fig. $3 C 2$, black; SEM indicated as width of the horizontal red bar around 0 ). The predicted DA level peaked at $135 \mathrm{~nm}$, but was also often statistically indistinguishable from of $0 \mathrm{~nm}$, with a nadir around two SDs below $0 \mathrm{~nm}$. Thus, the magnitude and type of the error in simulated data and experimental recordings seems similar, and the systematic bias is of the same order of magnitude as the statistical error.

We also compared the ability of our method to recover activation of presynaptic D2 autoreceptors (D2 ${ }^{\text {pre }}$ ) in the simulation (Fig. 3D1). The influence of D2 ${ }^{\text {pre }}$ autoreceptors on release probability was slightly underestimated since the estimated efficacy, $\beta$, was lower in our simple model (Fig. 3E1). Finally, we solve the equations for firing rate of DA neurons (Fig. 3F1,F2). Due to nonlinearity of the model, the uncertainty in predicted firing rate is the largest when predicted DA levels are low. However, the predicted firing rate follows a similar time course as the input. In the analysis of experimental data, where the real input firing rate is unknown, the estimated firing rate is consistent with electrophysiology (Grace and Bunney, 1984a,b; Hyland et al., 2002; Bingmer et al., 2011; Schiemann et al., 2012).

We next tested whether our analysis can make useful predictions of activation postsynaptic D1-like and D2-like receptors. Here we focused on phasic activation and inhibition of these receptors and the signaling cascades to which they are coupled (Dreyer, 2014). Our simplified analysis could reproduce the same activation by D1 and D2 receptors as in the simulation (Fig. $3 G 1, H 1$, compare black and blue). We also predicted the postsynaptic activation expected from the experimental recording (Fig. 3G2,H2). Here the amplitude and temporal patterns of activation were qualitatively similar compared with the simulation.

\section{Model parameters are similar in NAc core and shell}

The example above demonstrates that our model may extract novel and biologically relevant information from DA transients. We therefore analyzed DA levels in NAc shell $(N=19)$ and core $(N=17)$. We first determined $\gamma_{\mathrm{p}}$ and $V_{\max }$ for all animals (Fig. $4 A$ ). There was considerable variation between animals; $V_{\max }$ was in the range from $0.5 \mu \mathrm{M} / \mathrm{s}$ to $2 \mu \mathrm{M} / \mathrm{s}$ in both NAc core and shell, and $\gamma_{\mathrm{p}}$ was in the range from 20 to $100 \mathrm{~nm}$. We found no statistical difference between the NAc subregions for $V_{\max }$ (Two-sample, two tailed, Student's $t$ test: $p=0.58)$ or $\gamma_{p}(p=0.88)$. On the other hand, Calipari et al. (2012) have reported differences in DA release and uptake between NAc core and shell. However, the large between-subject variance in parameters and recording sites masks such differences in our study, although as also reported by Calipari et al. (2012), we found a strong correlation between $\gamma_{\mathrm{p}}$ and $V_{\max }(\rho=0.92, p<0.0001)$; on average $\gamma_{\mathrm{p}}$ is approximated by $\alpha V_{\max }$, with $\alpha=0.06 \mathrm{~s}^{-1}$ (Fig. $4 A$, red dashed line).

\section{Baseline and phasic DA levels are determined by efficacy of presynaptic D2 autoreceptors}

$C_{4 \mathrm{~Hz}}$, calculated using $\gamma_{\mathrm{p}}$ and $V_{\max }$ results, ranged from 20 to 80 $\mathrm{nM}$, with mean $\sim 49 \mathrm{nM}$ (Fig. $4 B$ ), which is in the same order of magnitude as recently reported experimentally by others (Atcherley et al., 2015). There was no significant difference in average DA levels between NAc core (mean $52 \mathrm{~nm}$ ) and shell (mean 47 $\mathrm{nM} ; p=0.15$ ), as previously observed with microdialysis (Cheng and Feenstra, 2006). If $C_{4 \mathrm{~Hz}}$ indeed provides a useful approximation of the true DA concentration, we should expect that the amplitude of DA fluctuations scale with baseline DA concentrations. Consistent with this prediction, we found the SD of FSCV recordings and $C_{4 \mathrm{~Hz}}$ to be correlated (Fig. $4 C ; \rho=0.52, p=$ $0.007)$. In the current model, the strength of the presynaptic feedback is determined by the efficacy $\beta$, which again is determined by the ratio of $\gamma_{\mathrm{p}}$ and $V_{\max }$ measured at the beginning of the experiment (Eq. 9). In practice, the degree of autoreceptor influence on DA release can be examined by measuring the rate of DA release after pharmacologically blocking autoreceptors. We therefore administered the D2/3 antagonist raclopride, and quantified the rate of DA release during electrical stimulation (24 pulses at $60 \mathrm{~Hz}$; Fig. 4D). For each individual rat, we quantified the experimental autoreceptor influence as the ratio $\gamma_{p}^{\mathrm{rac}} / \gamma_{p}$, where $\gamma_{p}^{\text {rac }}$ is defined as the maximal DA release rate during the 
A
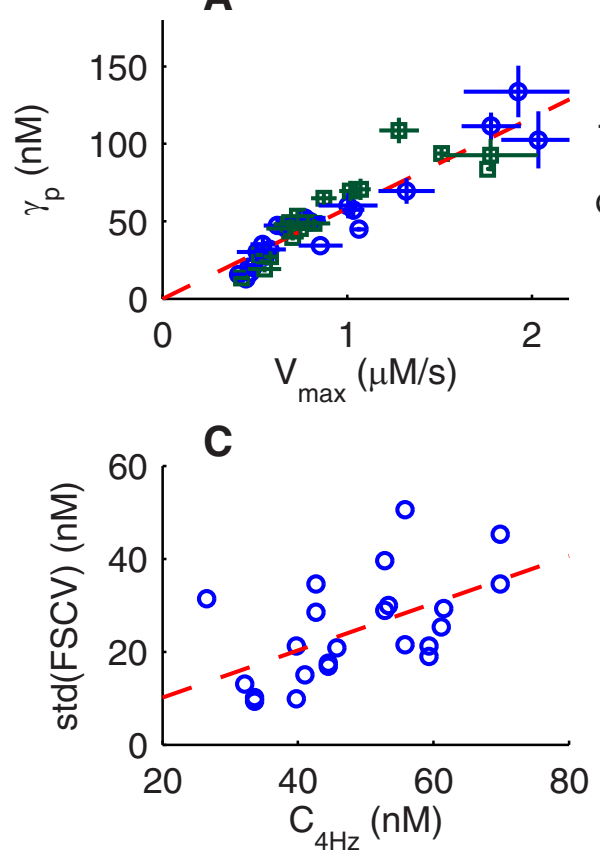

E

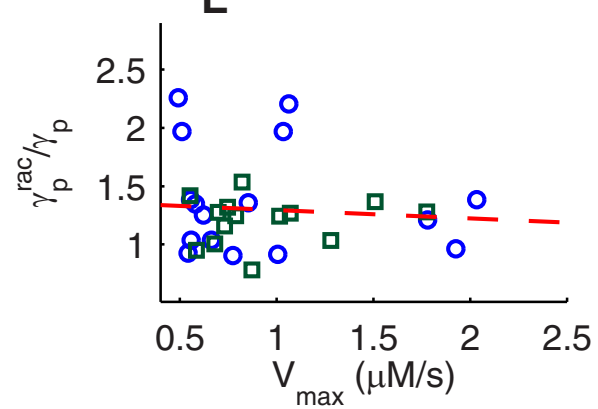

G

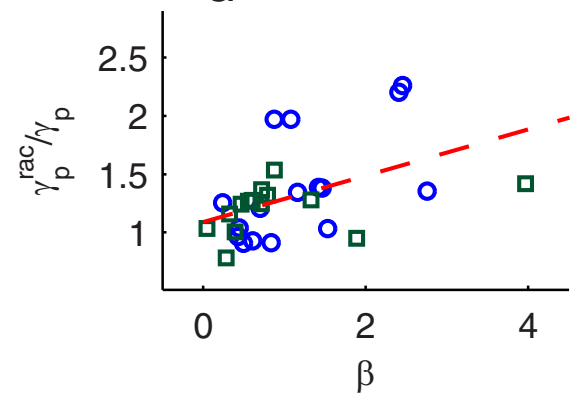

B

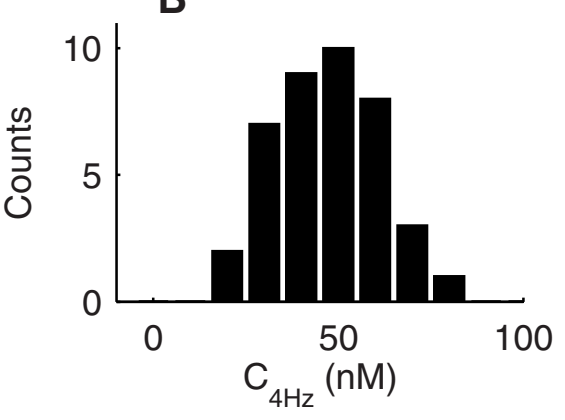

D

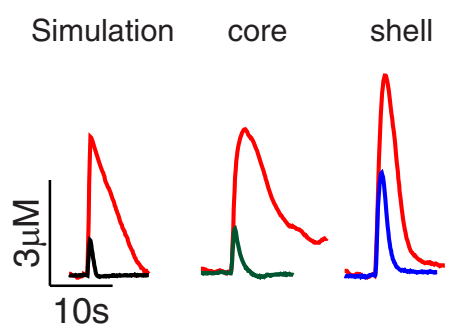

tion between the theoretical efficacy, $\beta$, and $\gamma_{p}^{\text {rac }} / \gamma_{p}$ (Fig. $4 G ; \rho=0.45, p=0.011$ ).

As such, our model shows autoreceptor efficacy to be a highly potent regulator of DA signaling. For example, $C_{4 \mathrm{~Hz}}$ is $\sim 20$ $\mathrm{nM}$ for $\beta=6,40 \mathrm{~nm}$ for $\beta=2,60 \mathrm{~nm}$ for $\beta=0.5$, and $>80 \mathrm{~nm}$ for $\beta=0$. Consequently, in animals with high DA levels, our model predicts that there will be only a minor increase in DA release after raclopride (because $\beta$ is low). However, in low DA animals, blocking D2/3 autoreceptors will give a large increase in evoked DA release (because $\beta$ is high). Thus, our model predicts a negative correlation between $C_{4 \mathrm{~Hz}}$ and the increase in DA release under autoreceptor blockade. Indeed, we found that the correlation between $\mathrm{C}_{4 \mathrm{~Hz}}$ and $\gamma_{p}^{\mathrm{rac}} / \gamma_{p}$ was negative, as predicted by our theory $(\rho=-0.84, p=0.0048$; Fig. $4 H)$. The observed correlation between $C_{4 \mathrm{~Hz}}$ and spontaneous fluctuations (Fig. 4C) with autoreceptor efficacy (Fig. $4 H$ ) indicates that $C_{4 \mathrm{~Hz}}$ provides a biologically meaningful approximation of the extracellular average DA concentration.

\section{Firing pattern determine postsynaptic} response under normal signaling

As described above, the link between extracellular DA concentration and release depends strongly on autoreceptor efficacy $\beta$. However, the information encoded by DA cell firing is itself mediated by DA levels, which according to our analysis can differ greatly between animals. We therefore asked how autoreceptor influence affects the decoding of DA cell firing patterns. We analyzed a representative recording in NAc shell, and then recalculated DA levels as they would have been realized under different autoreceptor control. The amplitude of DA levels proved to be strongly influenced by autoreceptor feedback, although their time course were relatively similar (Fig. 5A). Also, DA binding to high- and low-affinity DA receptors were qualitatively similar, but the absolute magnitudes reflected autoreceptor efficacy (Fig. $5 B, C$ ). However, we note that the postsynaptic response, when normalized by the amplitude of phasic signals (Dreyer, 2014), were quite similar (Fig. $5 D, E)$.

We also estimated the predicted postsynaptic activation using a predominantly tonic DA firing pattern. Again DA levels and receptor binding were dependent on $\beta$ (Fig. $6 A-C$ ), and postsynaptic activation was again independent on autoreceptor efficacy. However for this firing

transient, and is measured by the same means as $\gamma_{\mathrm{p}}$. The ratios $\gamma_{p}^{\mathrm{rac}} / \gamma_{p}$, did not differ in NAc core and shell. Furthermore, they did not correlate with $V_{\max }(\rho=-0.16, p=0.69$; Fig. $4 E)$ nor $\gamma_{\mathrm{p}}(\rho=$ $-0.41, p=0.09$; Fig. $4 F)$. However, there was a significant correla- pattern, the predicted activation of postsynaptic signals is much lower (Fig. 6D,E, compare with Fig. 5D,E). Thus, long-term differences in tonic and phasic DA signals between subjects can be 
compensated by plasticity of postsynaptic pathways. In particular, we note that strong autoreceptor regulation (for example, mediated by high expression of autoreceptors) will be associated with high gain of postsynaptic signals, which could be mediated by increased density of receptors and effectors.

NAc core and shell receives functionally distinct DA signals in freely moving rats

The analysis above indicates that DA firing patterns are the main determinant of the functional DA signal. However DA dynamics appear to be different in the NAc core and shell (Figs. 1, 2). The examples above (Figs. 5, 6), which are based on FSCV recordings in NAc shell and core, indicate that also the functional DA signal can be highly different between individuals. We therefore analyzed a number of FSCV recordings from these two regions, and asked whether the functional DA signal differs in NAc core and shell. In NAc shell, transients occasionally reached 200 nM, but phasically low DA levels, close to 0 nM, were often encountered (Fig. 7A1). In NAc core, the estimated DA concentration fluctuated only slightly $\sim C_{4 \mathrm{~Hz}}$ (Fig. $7 A 2, C$, compare blue and green). The predicted mean firing rates of VTA neurons innervating the NAc shell were in the range from 0 to $20 \mathrm{~Hz}$, and episodes of high and low firing rates were almost always brief (Fig. 7B1). On the other hand, the firing rate of VTA neurons projecting to NAc core varied only little (Fig. $7 B 2, D$, compare blue and green). In addition, the distribution of firing rates for NAc shellprojecting neurons showed a multimodal distribution (Fig. $7 D$, blue). When a trimodal Gaussian mixture model was fitted to the firing rates, peaks centered at $0.4 \pm$ $0.8,3.7 \pm 1.7$, and $6.5 \pm 2.1 \mathrm{~Hz}$ were detected (peak center \pm half-width at halfmaximum). In particular, the peak $\sim 0.4$ $\mathrm{Hz}$ suggests that firing patterns targeting NAc shell often included pauses (Fig. 7D, inset).

Thus, our analysis suggests that the increased variance observed in NAc shell recordings (Fig. 2) originates from synchronized phasic cell firing NAc shell projecting VTA DA neurons. On the other hand, the low variance typically observed in NAc core recordings originates from constant cell firing of NAc core projecting DA neurons. This difference in firing patterns gives a highly anatomically resolved postsynaptic activation in downstream targets (compare Figs. 5 and 6).

\section{NAc shell receives increased phasic DA under intravenous cocaine infusion}

Cocaine is a DA uptake inhibitor known to increase extracellular DA levels in terminal regions, preferentially in the NAc shell (Di
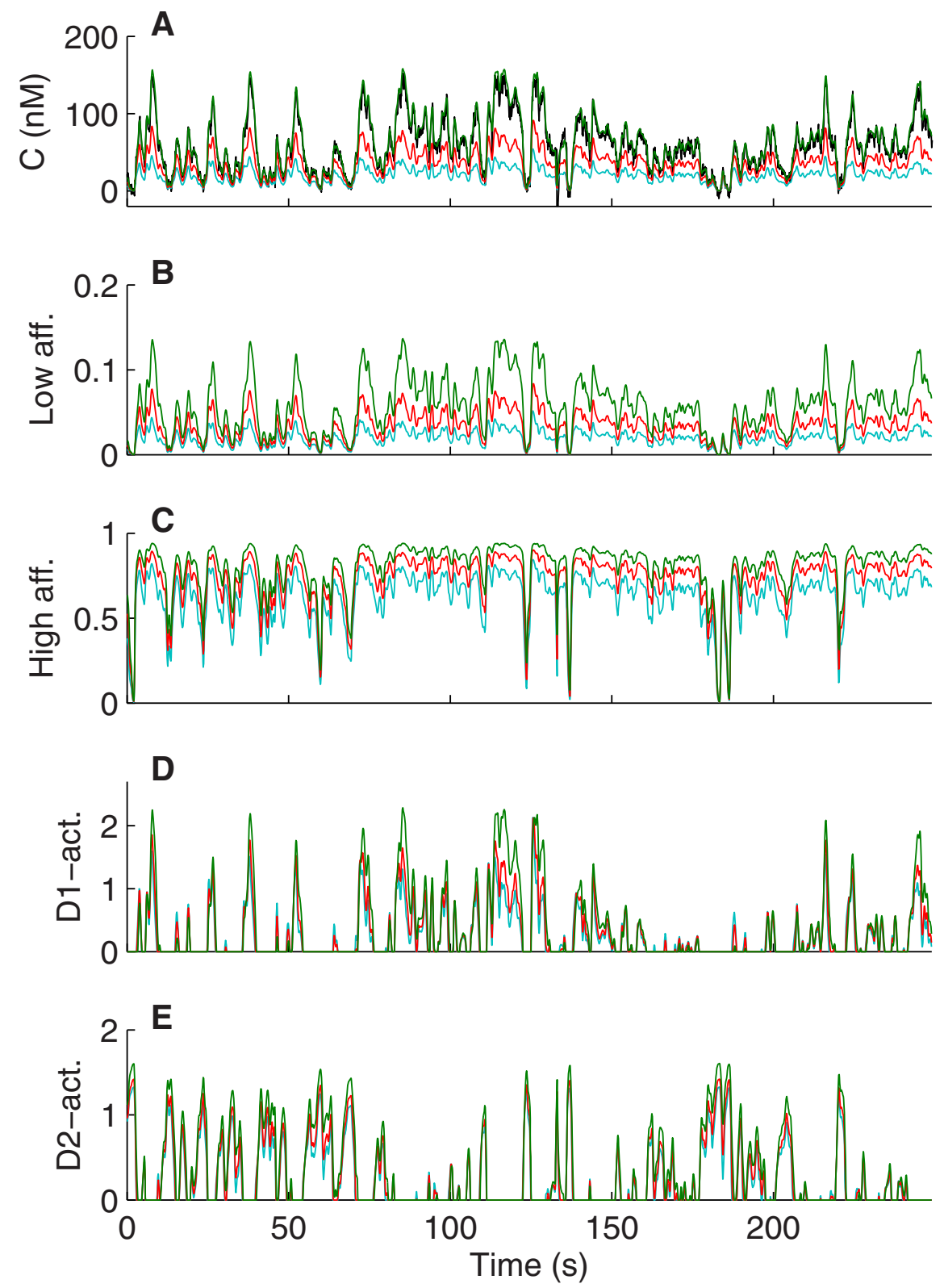

Figure 5. Autoreceptor control of DA levels and postsynaptic receptor activation expected for phasic DA cell firing. $A, D A$ ceptors at different values of $\beta$. C. Predicted binding to high-affinity receptors. D, Postsynaptic signals expected to be activated by $D 1$ receptors (Eq. 10). E, Postsynaptic signals expected to be disinhibited by D2 receptors (Eq. 11).

Chiara et al., 2004). It provides a highly salient and rewarding behavioral stimulus, but the details of its effects on DA signaling remain elusive. For example, in a recent study it was found in awake rats that in response to cocaine some midbrain DA neurons decreased their firing rate, whereas others increased both firing rate and degree of burst firing (Koulchitsky et al., 2012). However, with uptake inhibition, the link between cell firing and the perceived postsynaptic signal becomes highly skewed, and the functional effects of DA firing are hard to predict.

To address this issue, we applied our analysis to a set of FSCV recordings made after intravenous cocaine infusions (Aragona et al., 2008). After a bolus infusion, the concentration of cocaine in the brain is time-dependent, and causes a strong dynamic change in uptake inhibition during the experiment. We used a pharma- 

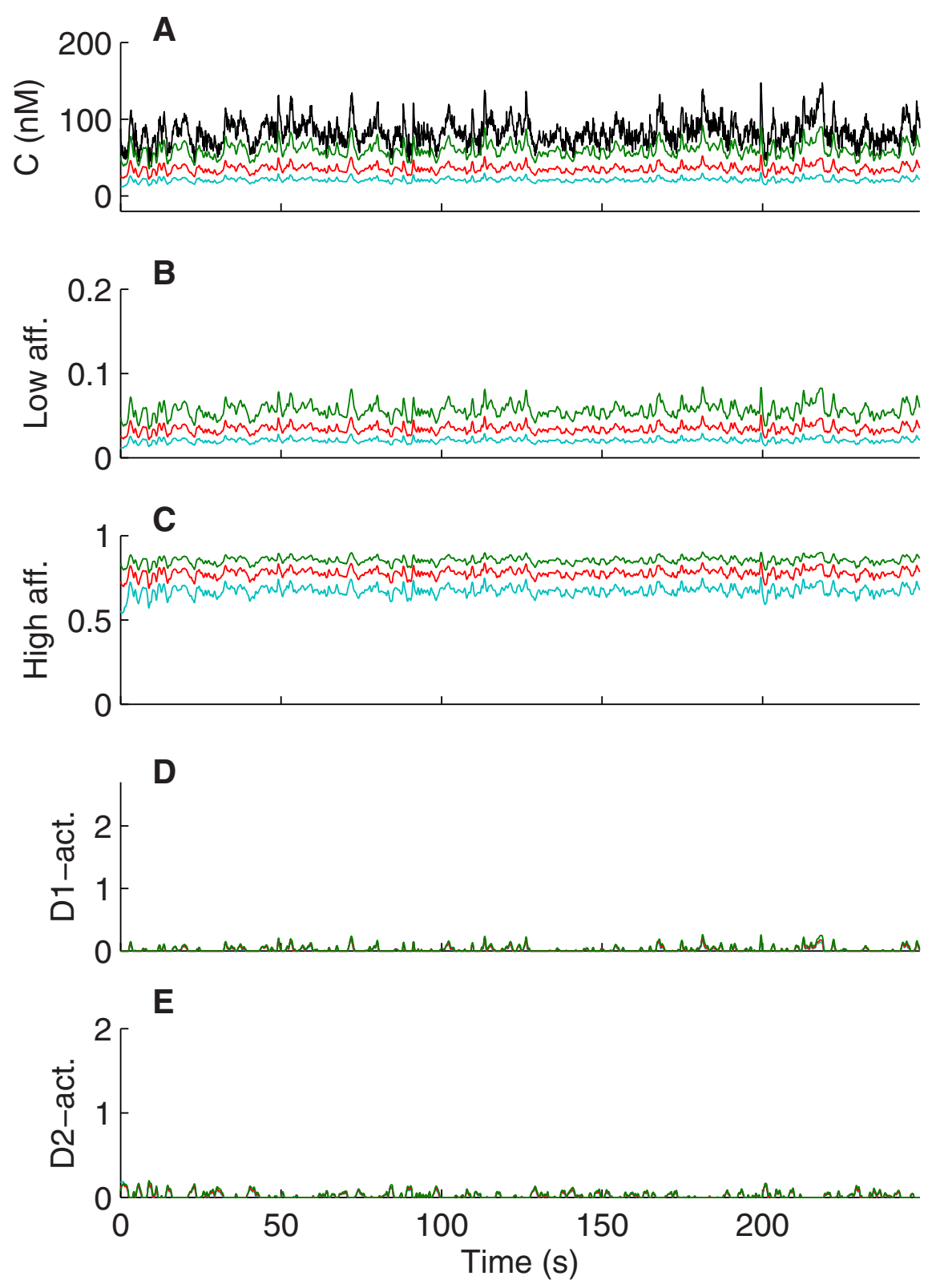

Figure 6. Influence of autoreceptor efficacy on tonic DA signaling. See also Figure 5. A, DA concentrations from experimental firing rate at different value of $\beta$. Black, FSCV recording from NAc core in freely moving rat, $\beta=0.05$ (experimental); green, $\beta=$ 0.5 ; red, $\beta=2$; cyan, $\beta=6$. B. Model predicted DA binding to low-affinity receptors at different values of $\beta$. C, Predicted binding to high-affinity receptors. $\boldsymbol{D}$, Postsynaptic signals expected to be activated by D1 receptors. $\boldsymbol{E}$, Same as in $\boldsymbol{D}$ but for D2 receptors.

cokinetic model to calculate the cerebral concentration of cocaine (Pan et al., 1991), and assumed that cocaine acts like a competitive DA uptake inhibitor with $K_{\mathrm{i}}=0.35 \mu \mathrm{M}$ (John and Jones, 2007). This enabled us to calculate a time-dependent apparent Michaelis-Menten constant $K_{\text {app }}(t)$ (Fig. 8A).

The FSCV recordings contained a $10 \mathrm{~s}$ pre-infusion segment. In our analysis, we fixed the average pre-infusion DA level to $C_{4 \mathrm{~Hz}}$ and used the post-infusion part to estimate DA levels during the cocaine condition (Fig. 8B1; B2 shows expanded view of B1). By correcting for the time dependent DA uptake and taking into account individual differences in autoreceptor efficacy, we were able to solve for firing rates of projection-specific VTA DA neurons. The post-cocaine firing rates were on average lower for neurons projecting to NAc core than for the shell (Fig. $8 C, D$, compare green and blue; $p=0.004$; mean taken $30-40 \mathrm{~s}$ after infusion, $n=5$ in each group). Furthermore, the post-cocaine firing pattern varied among NAcprojection subterritories. VTA neurons projecting to the NAc shell showed phasic firing, with both bursts and pauses (Fig. $8 C$, blue, for an example). We quantified the degree of phasic signaling by calculating the power spectrum of the firing rate between 0.3 and $0.8 \mathrm{~Hz}$ (Fig. $8 E$, compare blue with green, black, and cyan). Cocaine led to a significant increase in slow oscillations in NAc shell $(p=0.004$, twosample $t$ test), but not in the core ( $p=$ 0.45 , two-sample $t$ test). Furthermore, slow oscillations under cocaine were significantly larger in NAc shell than in core $(p=0.02)$. In the cocaine condition, the oscillations increased to a larger degree in NAc shell compared with core $(p=0.03$; Fig. 8F).

To test whether the observed range of DA levels after cocaine can be explained by current models of DA signals, we compared recorded DA levels with simulations using previously developed models (Dreyer and Hounsgaard, 2013). In the first simulation, DA release was driven by tonic firing and included regulation by both somatodendritic and presynaptic autoreceptors, as previously described (Dreyer and Hounsgaard, 2013). Mean $( \pm S D)$ terminal DA levels increased from $63 \pm 10 \mathrm{~nm}$ before cocaine to $200 \pm 15 \mathrm{nM}$ at $t=60 \mathrm{~s}$ after infusion (Fig. 8B2, red, mean value taken between 40 and $80 \mathrm{~s}$ post-infusion). The terminal release probability was reduced from $7.3 \pm 0.2 \%$ to $4.5 \pm 0.1 \%$, and the firing rate was reduced from 4 to $1 \mathrm{~Hz}$ (Fig. $8 C$, red). Thus, in the simulation, it was somatodendritic autoinhibition that accounted for the main blunting the DA response to cocaine challenge.

The simulated DA level and its intrinsic random variations were very similar to typical recordings in the NAc core (Fig. 8B2, compare green traces and red line). In contrast, DA levels recorded in NAc shell were all higher than predicted from the simulation, from 215 to $670 \%$ (Fig. $8 B 1$, compare blue traces and red line, $n=5$ ). With uptake inhibition, the input firing pattern used in the simulation has some effect on resulting DA levels. However, with a phasic input-firing pattern in the simulation, the predicted DA concentrations were approximately twofold higher than for tonic firing, but still not quite sufficient to reproduce typical NAc shell DA levels (data not shown).

We performed a second cocaine simulation where we adjusted reuptake, release, and terminal autoreceptors $\left(V_{\max }=0.7 \mu \mathrm{M} / \mathrm{s}\right.$, $\left.\gamma_{\mathrm{p}}=47 \mathrm{nM}, \beta=0.58\right)$ to match a particular NAc shell recording, where cocaine led to a particularly high increase in DA levels. 

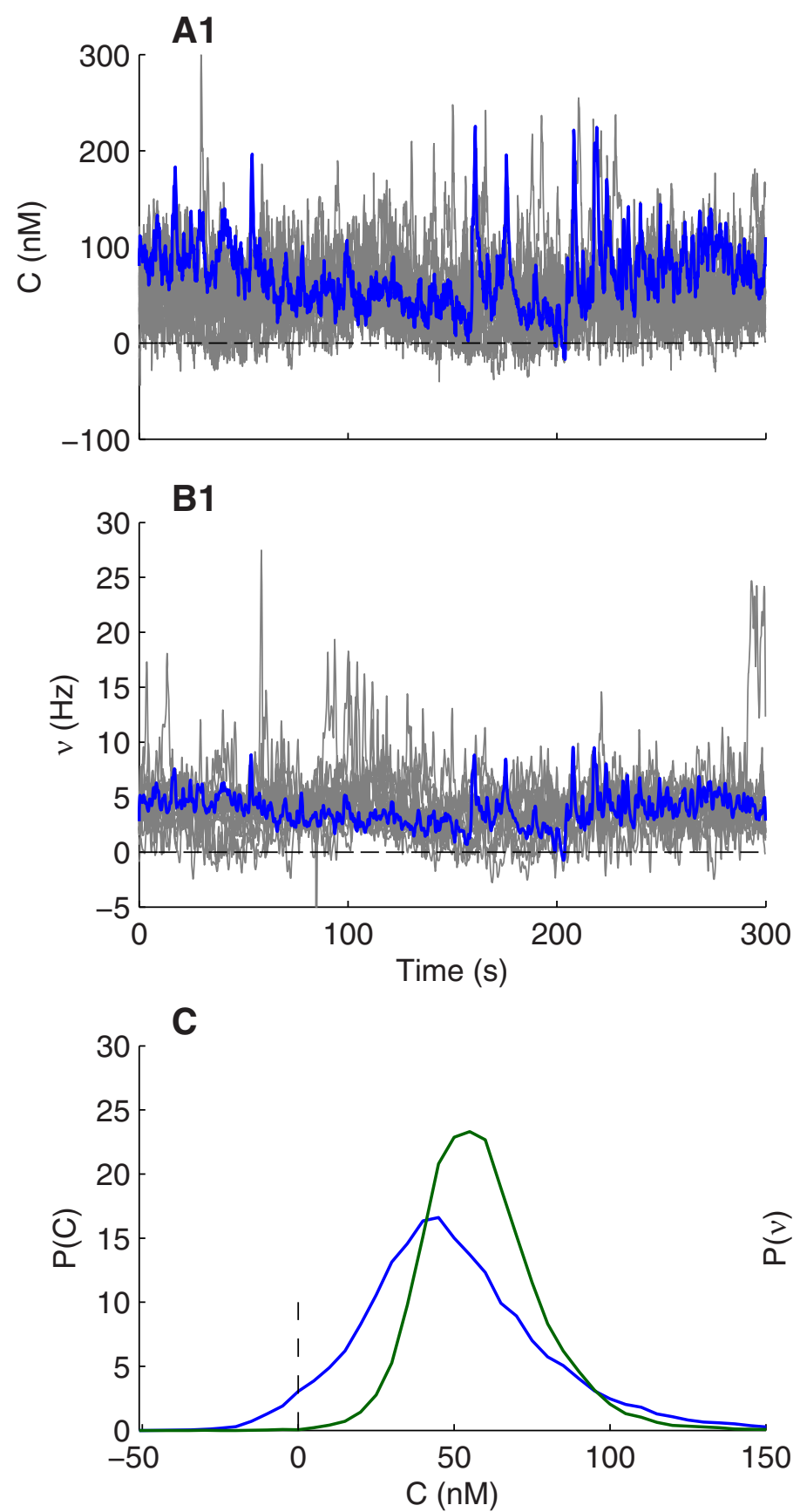

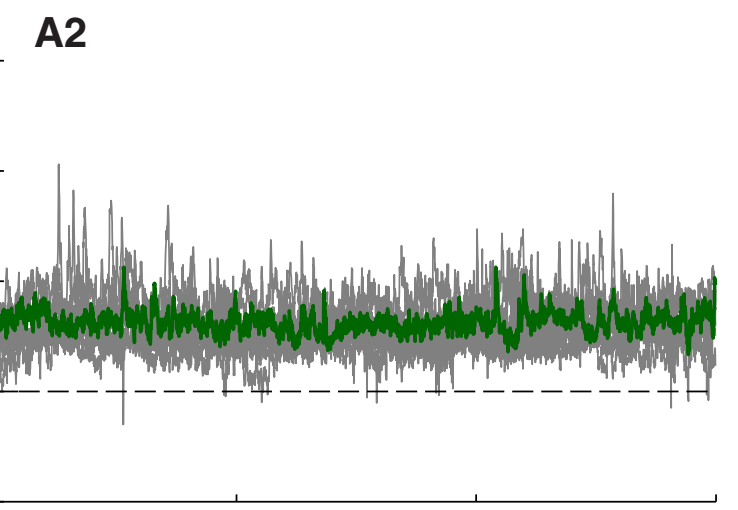

B2

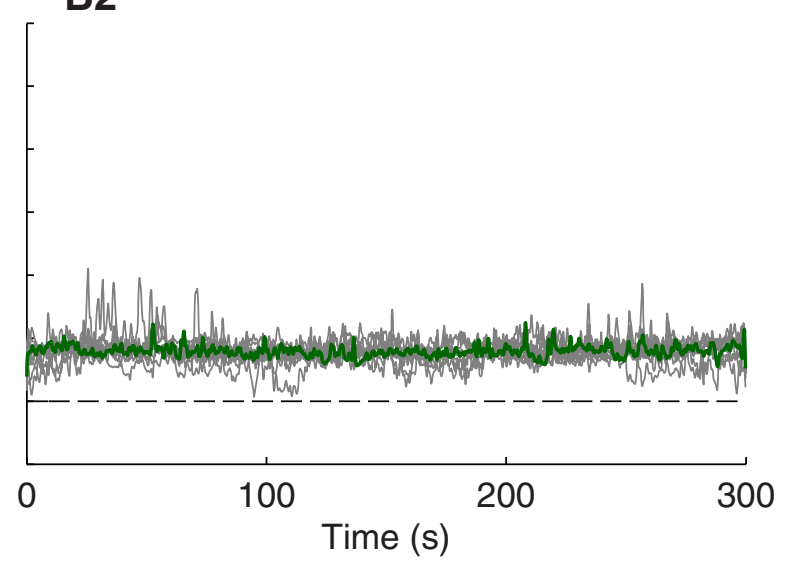

D

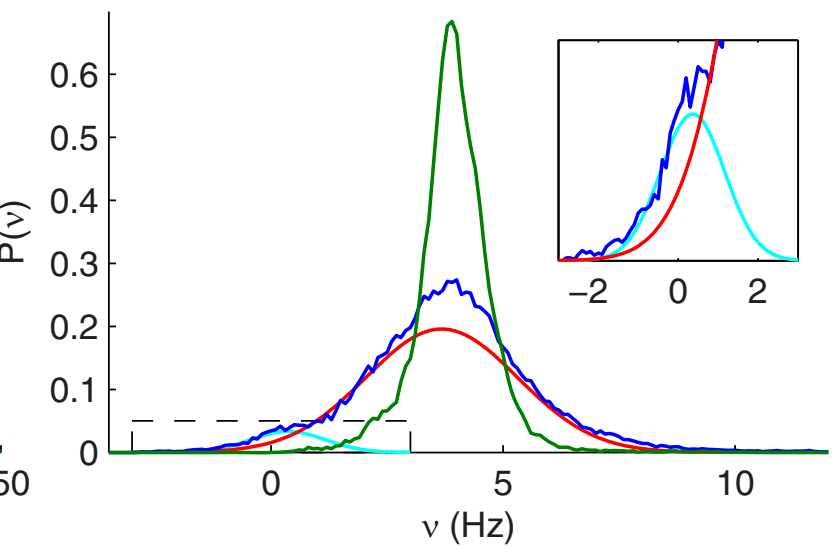

Figure 7. Analysis of baseline and intravenous saline data from $26 \mathrm{FSCV}$ recordings adjusted to $C_{4 \mathrm{~Hz}}$ predicted by Equation $3 . \boldsymbol{A}$, Sixteen traces from nine animals from NAc shell (gray), and a single representative recording (blue). $\boldsymbol{A 2}$, Ten traces from six animals from NAc core (gray), and a single representative recording (green). $\boldsymbol{B}$, Estimates of firing rates in the NAc shell, same colors as $\boldsymbol{A 1}$. B2, Estimates of firing rates in the NAc core, same colors as $\boldsymbol{A 2}$. C, All points histogram of DA levels in $\boldsymbol{A} \mathbf{1}$ and $\boldsymbol{A 2}$. Green, NAc core; blue, NAc shell. Vertical black dashed line indicates 0 nm. $\boldsymbol{D}$, All points histogram of estimated firing rates. NAc core, green; NAc shell, blue. NAc shell firing rates fitted with a Gaussian mixture model (red, peak at $3.7 \mathrm{~Hz}$; cyan, peak at $0.4 \mathrm{~Hz}$ ). Inset, NAc shell firing rates $\sim 0 \mathrm{~Hz}$ and Gaussian fits. Location of inset is indicated by black box in $\boldsymbol{D}$.

Furthermore, we bypassed the inhibition by somatodendritic autoreceptors, so that the tonic firing rate remained at $4 \mathrm{~Hz}$. With these settings, the computational model reproduced the magnitude of DA concentrations in NAc shell, but failed to capture the observed large fluctuations in DA concentration (Fig. 8B1, magenta).

Thus, we find that a model of DA signals from first principles model (Dreyer and Hounsgaard, 2013) wherein tonic DA release is modulated by somatodendritic and presynaptic autoreceptors is sufficient to describe the DA levels in NAc core after cocaine challenge (Fig. 8 B2, red). The same model can also reproduce NAc shell DA levels under cocaine when autoreceptor feedback is reduced (Fig. $8 B 1$, magenta). The agreement between the low feedback simulation and FSCV data in NAc shell DA levels does not imply that lack of somatodendritic autoinhibition explains the difference in cocaine effects between NAc core and shell observed here, and by others (Di Chiara et al., 2004). In particular, NMDA receptors are required for both tonic and phasic response to cocaine in NAc shell (Sombers et al., 2009), suggesting that excitatory afferents to NAc shell-projecting DA neurons may in some circumstances overrule somatodendritic autoinhibition during cocaine challenge. 

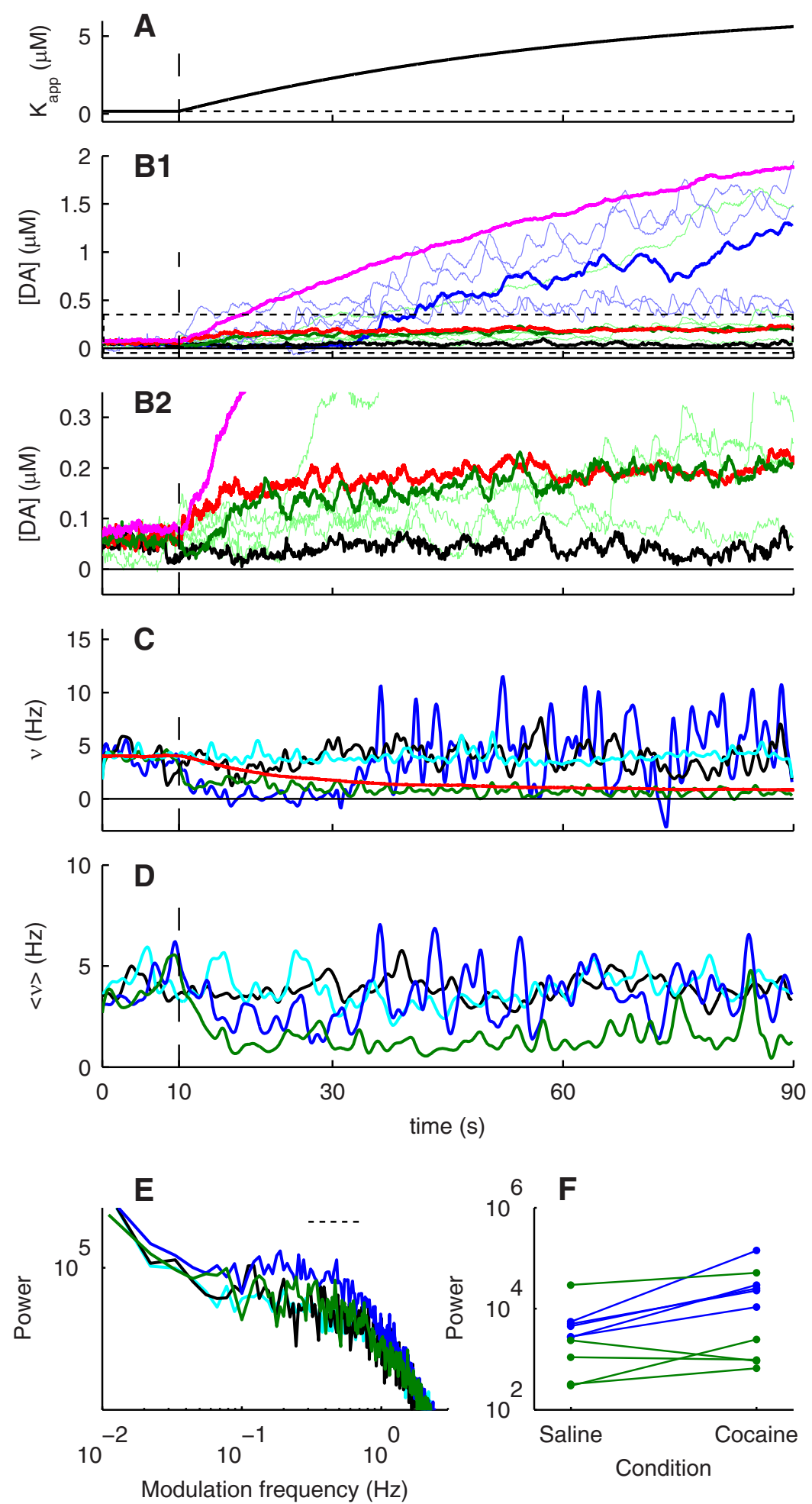

Figure 8. Analysis of DA signals during in the intravenous cocaine treatment condition. Vertical black line in $\boldsymbol{A}-\boldsymbol{E}$ indicates time point of the cocaine/saline infusion. $\boldsymbol{A}$, Dynamic apparent Michaelis-Menten constant used in the analysis (solid); pre-infusion value of $K_{\text {app }}$ (dashed). B1, DA concentrations from FSCV recordings; pre-infusion average set to $C_{4 \mathrm{~Hz}}$. Blue, NAc shell; green, NAc core; black, saline NAC shell; red, simulation with high feedback ( $\beta=1.25$ and somatodendritic autoinhibition); magenta, simulation with low feedback ( $\beta=$ 0.58 and no somatodendritic autoinhibition). Same traces are highlighted in Cand D. Black dashed lines indicate region expanded in B2. B2, Expanded view of $\boldsymbol{B} 1$, showing data with low-amplitude responses to cocaine. Data includes saline infusion condition (black), NAc core (green), and high feedback simulation (red). C, Firing rates calculated for VTA neurons for highlighted traces in $\boldsymbol{B}$ and $\boldsymbol{C}$. $\boldsymbol{D}$, Average of calculated firing rates for VTA neurons projecting to NAc core $(n=5)$ and NAc shell $(n=5)$, under cocaine treatment condition (green and blue), and compared with saline infusion condition (cyan and black). $\boldsymbol{E}$, Power spectra of calculated firing rate. Blue, NAc shell, cocaine; green: NAc core, cocaine; black: NAc shell, saline; cyan: NAc core, saline. Dashed line indicates range of VTA firing frequencies used in G. G, Average modulation power under saline and cocaine conditions. Blue, NAc shell; green: NAc core.
In the present analysis, the autoreceptor efficacy is determined from pre-drugevoked release. Therefore, DA levels recorded under the cocaine condition serves as another critical test of our model. The observed DA concentrations under cocaine were fully consistent with the model: recordings in animals with low $\beta$ tended to have high increases in DA under cocaine, and in recordings from animals with high $\beta$, the increase in DA was relatively low. However, as observed above, the firing rate of DA neurons played the most important role in determining the cocaine response, such that $\beta$ alone did not predict the DA level under cocaine.

\section{Discussion}

Here we combine computational modeling, mathematical analysis, and FSCV to provide a novel analysis of dynamic DA levels in the NAc of the freely moving rat. The model calculates firing rates of VTA neurons from recorded DA levels, and thereby directly addresses the causal relationship between target-specific neuronal firing patterns, extracellular DA, and signaling at presynaptic and postsynaptic DA receptors.

The FSCV data show fluctuations relative to baseline DA levels, but the baseline itself is unknown. As such, the underlying Michaelis-Menten equation (Eq. 1) is underdetermined, but can be qualified through the additional constraint that the long-term average of DA neuron firing is 4 $\mathrm{Hz}$, as is reported experimentally (Grace and Bunney, 1984a,b). Furthermore, our model shows that individual differences in extracellular DA can be attributed to differing strength of presynaptic autoreceptor feedback. It might be supposed that other approaches would serve to relate FSCV data with a functional output. For example, one might assume that the extracellular DA is the same for all animals, and then solve for firing rate, in a scenario where individuals with a low DA release-uptake ratio will be assigned a high neuron-firing rate. However, this approach cannot explain why spontaneous fluctuations scale with maximal DA release rate in the NAc shell (Fig. 2A). Similarly, the low fluctuations in NAc core could be taken as indications that average DA is lower in NAc core compared with shell. However, this interpretation fails because the response to raclopride challenge is similar in NAc shell and core. Our model reproduces main features of DA signaling across a population of rats even when challenged pharmacologically. We therefore consider the model presented 
here to be the best possible, given current experimental limitations.

A compelling feature of our model lies in its fitness to account for scaling of the variance of the DA signal to baseline, for individual effect of raclopride and cocaine challenges, and provides a view of real-time dynamical DA cell signaling. However, we assume that DA cell firing is on average exactly $4 \mathrm{~Hz}$. Single-cell firing rates, often found between 2 and $6 \mathrm{~Hz}$, certainly deviate from that. However as our model reports the average firing rate of $\sim 100$ VTA neurons (Matsuda et al., 2009), the deviation at the group level is likely to be less. However, some variations in the real average firing rate must occur in our dataset also and there may be experimental conditions were the mean firing rate deviate substantially from the literature value. We found, however, our results to be robust to a $\pm 1 \mathrm{~Hz}$ deviation in firing rate, which results in $25 \%$ shifts in the calculated mean DA level and with minor qualitative differences in predictions. We also found that the distribution of firing rates calculated from NAc shell recordings had a secondary peak at $0.4 \pm 0.8 \mathrm{~Hz}$ (Fig. $7 D$ ) indicating that global pauses are a prominent functional feature of the firing pattern indicating that our method can resolve these with $\sim 1 \mathrm{~Hz}$ accuracy.

In the model presented here, DA is the sole modulator of presynaptic terminal DA release and DA cell firing is the only source of DA release. However, DA release may be influenced by cholinergic interneurons (Zhang and Sulzer, 2004; Cragg, 2006; Threlfell et al., 2012). In the present data, we did not observe strong violations to Equation 1 that would force us to increase the complexity of the model to accommodate such effects. However, our current model can be extended, for example by redefining $\gamma(t)$ to account for modulation of release probability, or by introducing an "apparent" firing rate, to account for DA release not depending on DA cell firing.

There is growing awareness that VTA DA neurons express complex orchestrated responses to different stimuli (BrombergMartin et al., 2010; Lammel et al., 2011, 2012; Roeper, 2013). At the same time, NAc core and shell have been assigned opposing roles in the control of behavior (Dalley et al., 2011; Ito and Hayen, 2011). However, the real-time nature of the DA signals conveyed by subclasses of VTA neurons is difficult to investigate by direct experiment. We applied our model to derive group-level cell activity of DA neuron populations to the NAc core and shell, and found that these neuron groups exhibit dichotomous activity in freely moving animals. According to our model, NAc shell received strong DA phasic inputs while the NAc core received a constant, tonic DA input. The DA signals appear to sufficient to activate both D1- and D2-like postsynaptic pathways in the NAc shell, but not always in the NAc core (compare Figs. 5 and 6). This difference between the NAc core and shell signaling could be consequence of the particular behavioral paradigm, where the rat is moving in a relatively (but not completely) novel environment. Thus, the dichotomous DA signaling need not generalize to all behavioral paradigms; for example, the DA release pattern in the NAc core might differ had the test chamber been previously associated with salient stimuli. However, the anatomical differentiation of our deduced VTA firing rates persisted after infusion of cocaine, which caused a slow $0.2-1 \mathrm{~Hz}$, modulation of VTA neuron firing rates for the NAc innervation. At the level of single trials, slow bursts and pauses were often found in an alternating pattern. Similar firing pattern has been observed in anesthetized animals under cocaine and D2/3 receptor blockade (Zhou et al., 2006). Had the observed sequence of bursts and pauses occurred in the absence of the uptake inhibition, it would be expected to engage D1- and D2-regulated postsynaptic pathways in an alternating temporal pattern. However, in our model the postsynaptic signal is also strongly influenced by reduced DA uptake. When this is taken into account, the predicted DA signal evokes only a phasic D1 signal, strong in the NAc shell and slightly lower in the NAc core. On the other hand, phasic D2 signals, losing sensitivity to pauses in cell firing, would be absent both in shell and core; this model-based prediction is in overall agreement with studies of functional effects of cocaine (Svenningsson et al., 2000; BertranGonzalez et al., 2008).

We assume that DA cell firing drives a purely temporal DA signal in NAc, but with functionally distinct signals at NAc divisions. Our model of DA signaling at postsynaptic DA receptors may be viewed as a physiologically derived equivalent of schemes developed from reinforcement learning paradigms (Frank, 2005; Frank and O'Reilly, 2006; Hikosaka, 2007; Gurney et al., 2015). However, the condition under which we recorded baseline activity does not involve direct experimentally controlled reinforcement, as noted above. Nevertheless, the model depicts phasic DA signals in NAc shell presenting both bursts and pauses in VTA neurons innervating the NAc shell. In fact, both bursts and pauses were present, and even exaggerated, during highly reinforcing cocaine administration.

Our theory assumes that individual differences in autoreceptor efficacy explain the large variation in prevailing dopamine concentrations, which ranged from 20 to $100 \mathrm{~nm}$ across the population (Figs. $4 B, 5$ ). This leads to the prediction of a negative correlation between individual DA baseline and the effect of raclopride on evoked DA transients (Fig. 4), which we confirmed by experiment. Although many physiological factors might influence the prevailing DA level in individuals, only variations in autoreceptors efficacy are apt to account for the observed negative correlation between DA levels and the increase in DA release under D2 blockade (Fig. 4H). For example, if individual differences in DAT expression or DA synthesis would account for the observed differences in DA levels $\left(C_{4 \mathrm{~Hz}}\right)$, low DA levels would lead to less increase in DA release after raclopride than high DA levels, in contrast to what we observe (Fig. $4 H$ ). However, even though we argue that autoreceptors provide the dominant influence on DA levels, other factors may of course also play a role.

Individual differences in reinforcement learning and choice behavior have often been attributed to trait differences in D2 autoreceptor activation (Frank and O'Reilly, 2006; Cools et al., 2009; Jocham et al., 2011). Indeed, correlations similar to those we report here have been reported for effects of somatodendritic autoreceptors on cocaine self-administration in rats (Marinelli and White, 2000), novelty seeking in humans (Zald et al., 2008), and impulsivity and DA release under amphetamine challenge (Buckholtz et al., 2010). In our model, the magnitude of transient spikes and dips in extracellular DA arising from bursts and pauses in DA neuron firing depends on autoreceptor efficacy, as defined parameter via the parameter $\beta$. However, the resulting postsynaptic signaling depends not only on the amplitude of the DA transient, but also on coupling of intracellular postsynaptic cascades to fluctuations in extracellular DA. In our model, we assumed that this coupling sensitivity is inversely proportional to $\gamma_{\mathrm{p}}$ (Eqs. 10, 11). This assumption leads to postsynaptic activation being qualitatively similar, regardless of baseline autoreceptor efficacy (Figs. 5, 6). The model also predicts minor differences in the postsynaptic signal; for example, the disinhibition of D2 regulated postsynaptic pathways by a single firing pause is $\sim 40 \%$ higher when autoreceptor efficacy is set low (using Eq. 11, data 
not shown). However, such differences are highly dependent on particular model assumptions and should therefore be interpreted with caution. We believe that present results can serve as the foundation of a more detailed model of postsynaptic activation, which may be informative about how autoreceptors shape individual differences in the rate of learning.

In summary, we present an analysis of presynaptic and postsynaptic DA signals based on FCSV recordings in freely moving rats. The model, which is based upon physiologically plausible constraints, imparts unique insight into the neuronal activity producing real-time DA signaling in functional divisions of the NAc during spontaneous activity, and under conditions of pharmacological challenge.

\section{References}

Aragona BJ, Cleaveland NA, Stuber GD, Day JJ, Carelli RM, Wightman RM (2008) Preferential enhancement of dopamine transmission within the nucleus accumbens shell by cocaine is attributable to a direct increase in phasic dopamine release events. J Neurosci 28:8821-8831. CrossRef Medline

Arbuthnott GW, Wickens J (2007) Space, time and dopamine. Trends Neurosci 30:62-69. CrossRef Medline

Atcherley CW, Wood KM, Parent KL, Hashemi P, Heien ML (2015) The coaction of tonic and phasic dopamine dynamics. Chem Commun (Camb) 51:2235-2238. CrossRef Medline

Badrinarayan A, Wescott SA, Vander Weele CM, Saunders BT, Couturier BE, Maren S, Aragona BJ (2012) Aversive stimuli differentially modulate real-time dopamine transmission dynamics within the nucleus accumbens core and shell. J Neurosci 32:15779-15790. CrossRef Medline

Bertran-Gonzalez J, Bosch C, Maroteaux M, Matamales M, Hervé D, Valjent E, Girault JA (2008) Opposing patterns of signaling activation in dopamine D1 and D2 receptor-expressing striatal neurons in response to cocaine and haloperidol. J Neurosci 28:5671-5685. CrossRef Medline

Bingmer M, Schiemann J, Roeper J, Schneider G (2011) Measuring burstiness and regularity in oscillatory spike trains. J Neurosci Methods 201: 426-437. CrossRef Medline

Bromberg-Martin ES, Matsumoto M, Hikosaka O (2010) Dopamine in motivational control: rewarding, aversive, and alerting. Neuron 68:815-834. CrossRef Medline

Buckholtz JW, Treadway MT, Cowan RL, Woodward ND, Li R, Ansari MS, Baldwin RM, Schwartzman AN, Shelby ES, Smith CE, Kessler RM, Zald DH (2010) Dopaminergic network differences in human impulsivity. Science 329:532. CrossRef Medline

Calipari ES, Huggins KN, Mathews TA, Jones SR (2012) Conserved dorsalventral gradient of dopamine release and uptake rate in mice, rats and rhesus macaques. Neurochem Int 61:986-991. CrossRef Medline

Cheng J, Feenstra MG (2006) Individual differences in dopamine efflux in nucleus accumbens shell and core during instrumental learning. Learn Mem 13:168-177. CrossRef Medline

Cools R, Frank MJ, Gibbs SE, Miyakawa A, Jagust W, D’Esposito M (2009) Striatal dopamine predicts outcome-specific reversal learning and its sensitivity to dopaminergic drug administration. J Neurosci 29:1538-1543. CrossRef Medline

Cragg SJ (2006) Meaningful silences: how dopamine listens to the ACh pause. Trends Neurosci 29:125-131. CrossRef Medline

Cragg SJ, Rice ME (2004) DAncing past the DAT at a DA synapse. Trends Neurosci 27:270-277. CrossRef Medline

Cumming P (2011) Absolute abundances and affinity states of dopamine receptors in mammalian brain: a review. Synapse 65:892-909. CrossRef Medline

Dalley JW, Everitt BJ, Robbins TW (2011) Impulsivity, compulsivity, and top-down cognitive control. Neuron 69:680-694. CrossRef Medline

Di Chiara G, Bassareo V, Fenu S, De Luca MA, Spina L, Cadoni C, Acquas E, Carboni E, Valentini V, Lecca D (2004) Dopamine and drug addiction: the nucleus accumbens shell connection. Neuropharmacology 47: 227-241. CrossRef Medline

Dreyer JK (2014) Three mechanisms by which striatal denervation causes breakdown of dopamine signaling. J Neurosci 34:12444-12456. CrossRef Medline

Dreyer JK, Hounsgaard J (2013) Mathematical model of dopamine autore- ceptors and uptake inhibitors and their influence on tonic and phasic dopamine signaling. J Neurophysiol 109:171-182. CrossRef Medline

Dreyer JK, Herrik KF, Berg RW, Hounsgaard JD (2010) Influence of phasic and tonic dopamine release on receptor activation. J Neurosci 30:1427314283. CrossRef Medline

Frank MJ (2005) Dynamic dopamine modulation in the basal ganglia: a neurocomputational account of cognitive deficits in medicated and nonmedicated Parkinsonism. J Cogn Neurosci 17:51-72. CrossRef Medline

Frank MJ, O'Reilly RC (2006) A mechanistic account of striatal dopamine function in human cognition: psychopharmacological studies with cabergoline and haloperidol. Behav Neurosci 120:497-517. CrossRef Medline

Grace AA (2000) The tonic/phasic model of dopamine system regulation and its implications for understanding alcohol and psychostimulant craving. Addiction 95:119-128. CrossRef Medline

Grace AA, Bunney BS (1984a) The control of firing pattern in nigral dopamine neurons: burst firing. J Neurosci 4:2877-2890. Medline

Grace AA, Bunney BS (1984b) The control of firing pattern in nigral dopamine neurons: single spike firing. J Neurosci 4:2866-2876. Medline

Groenewegen HJ, Wright CI, Beijer AV, Voorn P (1999) Convergence and segregation of ventral striatal inputs and outputs. Ann N Y Acad Sci 877: 49-63. CrossRef Medline

Gurney KN, Humphries MD, Redgrave P (2015) A new framework for cortico-striatal plasticity: behavioural theory meets in vitro data at the reinforcement-action interface. PLoS Biol 13:e1002034. CrossRef Medline

Heien ML, Khan AS, Ariansen JL, Cheer JF, Phillips PE, Wassum KM, Wightman RM (2005) Real-time measurement of dopamine fluctuations after cocaine in the brain of behaving rats. Proc Natl Acad Sci U S A 102:1002310028. CrossRef Medline

Hikosaka O (2007) Basal ganglia mechanisms of reward-oriented eye movement. Ann N Y Acad Sci 1104:229-249. CrossRef Medline

Hyland BI, Reynolds JN, Hay J, Perk CG, Miller R (2002) Firing modes of midbrain dopamine cells in the freely moving rat. Neuroscience 114:475492. CrossRef Medline

Ito R, Hayen A (2011) Opposing roles of nucleus accumbens core and shell dopamine in the modulation of limbic information processing. J Neurosci 31:6001-6007. CrossRef Medline

Jocham G, Klein TA, Ullsperger M (2011) Dopamine-mediated reinforcement learning signals in the striatum and ventromedial prefrontal cortex underlie value-based choices. J Neurosci 31:1606-1613. CrossRef Medline

John CE, Jones SR (2007) Voltammetric characterization of the effect of monoamine uptake inhibitors and releasers on dopamine and serotonin uptake in mouse caudate-putamen and substantia nigra slices. Neuropharmacology 52:1596-1605. CrossRef Medline

Keithley RB, Wightman RM (2011) Assessing principal component regression prediction of neurochemicals detected with fast-scan cyclic voltammetry. Acs Chem Neurosci 2:514-525. CrossRef Medline

Keithley RB, Heien ML, Wightman RM (2009) Multivariate concentration determination using principal component regression with residual analysis. Trends Analyt Chem 28:1127-1136. CrossRef Medline

Koulchitsky S, De Backer B, Quertemont E, Charlier C, Seutin V (2012) Differential effects of cocaine on dopamine neuron firing in awake and anesthetized rats. Neuropsychopharmacology 37:1559-1571. CrossRef Medline

Lammel S, Ion DI, Roeper J, Malenka RC (2011) Projection-specific modulation of dopamine neuron synapses by aversive and rewarding stimuli. Neuron 70:855-862. CrossRef Medline

Lammel S, Lim BK, Ran C, Huang KW, Betley MJ, Tye KM, Deisseroth K, Malenka RC (2012) Input-specific control of reward and aversion in the ventral tegmental area. Nature 491:212-217. CrossRef Medline

Marcott PF, Mamaligas AA, Ford CP (2014) Phasic dopamine release drives rapid activation of striatal D2-receptors. Neuron 84:164-176. CrossRef Medline

Marinelli M, White FJ (2000) Enhanced vulnerability to cocaine selfadministration is associated with elevated impulse activity of midbrain dopamine neurons. J Neurosci 20:8876-8885. Medline

Matsuda W, Furuta T, Nakamura KC, Hioki H, Fujiyama F, Arai R, Kaneko T (2009) Single nigrostriatal dopaminergic neurons form widely spread and highly dense axonal arborizations in the neostriatum. J Neurosci 29:444-453. CrossRef Medline 
Murphy ER, Robinson ES, Theobald DE, Dalley JW, Robbins TW (2008) Contrasting effects of selective lesions of nucleus accumbens core or shell on inhibitory control and amphetamine-induced impulsive behaviour. Eur J Neurosci 28:353-363. CrossRef Medline

Owesson-White CA, Ariansen J, Stuber GD, Cleaveland NA, Cheer JF, Wightman RM, Carelli RM (2009) Neural encoding of cocaine-seeking behavior is coincident with phasic dopamine release in the accumbens core and shell. Eur J Neurosci 30:1117-1127. CrossRef Medline

Paladini CA, Roeper J (2014) Generating bursts (and pauses) in the dopamine midbrain neurons. Neuroscience 282C:109-121. CrossRef Medline

Pan HT, Menacherry S, Justice JB Jr (1991) Differences in the pharmacokinetics of cocaine in naive and cocaine-experienced rats. J Neurochem 56:1299-1306. CrossRef Medline

Pan PY, Ryan TA (2012) Calbindin controls release probability in ventral tegmental area dopamine neurons. Nat Neurosci 15:813-815. CrossRef Medline

Porter-Stransky KA, Wescott SA, Hershman M, Badrinarayan A, Vander Weele CM, Lovic V, Aragona BJ (2011) Cocaine must enter the brain to evoke unconditioned dopamine release within the nucleus accumbens shell. Neurosci Lett 504:13-17. CrossRef Medline

Pothuizen HH, Jongen-Rêlo AL, Feldon J, Yee BK (2005) Double dissociation of the effects of selective nucleus accumbens core and shell lesions on impulsive-choice behaviour and salience learning in rats. Eur J Neurosci 22:2605-2616. CrossRef Medline

Richfield EK, Penney JB, Young AB (1989) Anatomical and affinity state comparisons between dopamine D1 and D2 receptors in the rat central nervous system. Neuroscience 30:767-777. CrossRef Medline

Robinson DL, Venton BJ, Heien ML, Wightman RM (2003) Detecting subsecond dopamine release with fast-scan cyclic voltammetry in vivo. Clin Chem 49:1763-1773. CrossRef Medline

Roeper J (2013) Dissecting the diversity of midbrain dopamine neurons. Trends Neurosci 36:336-342. CrossRef Medline

Salamone JD, Correa M (2012) The mysterious motivational functions of mesolimbic dopamine. Neuron 76:470-485. CrossRef Medline

Schiemann J, Schlaudraff F, Klose V, Bingmer M, Seino S, Magill PJ, Zaghloul KA, Schneider G, Liss B, Roeper J (2012) K-ATP channels in dopamine substantia nigra neurons control bursting and novelty-induced exploration. Nat Neurosci 15:1272-1280. CrossRef Medline

Schmitz Y, Benoit-Marand M, Gonon F, Sulzer D (2003) Presynaptic regulation of dopaminergic neurotransmission. J Neurochem 87:273-289. CrossRef Medline

Schultz W (2010) Dopamine signals for reward value and risk: basic and recent data. Behav Brain Funct 6:24. CrossRef Medline

Skinbjerg M, Sibley DR, Javitch JA, Abi-Dargham A (2012) Imaging the high-affinity state of the dopamine D2 receptor in vivo: fact or fiction? Biochem Pharmacol 83:193-198. CrossRef Medline

Sokolowski JD, Salamone JD (1998) The role of accumbens dopamine in lever pressing and response allocation: effects of 6-OHDA injected into core and dorsomedial shell. Pharmacol Biochem Behav 59:557-566. CrossRef Medline

Sombers LA, Beyene M, Carelli RM, Wightman RM (2009) Synaptic overflow of dopamine in the nucleus accumbens arises from neuronal activity in the ventral tegmental area. J Neurosci 29:1735-1742. CrossRef Medline

Svenningsson P, Lindskog M, Ledent C, Parmentier M, Greengard P, Fredholm BB, Fisone G (2000) Regulation of the phosphorylation of the dopamine- and cAMP-regulated phosphoprotein of $32 \mathrm{kDa}$ in vivo by dopamine D1, dopamine D2, and adenosine A2A receptors. Proc Natl Acad Sci U S A 97:1856-1860. CrossRef Medline

Threlfell S, Lalic T, Platt NJ, Jennings KA, Deisseroth K, Cragg SJ (2012) Striatal dopamine release is triggered by synchronized activity in cholinergic interneurons. Neuron 75:58-64. CrossRef Medline

Vander Weele CM, Porter-Stransky KA, Mabrouk OS, Lovic V, Singer BF, Kennedy RT, Aragona BJ (2014) Rapid dopamine transmission within the nucleus accumbens: dramatic difference between morphine and oxycodone delivery. Eur J Neurosci 40:3041-3054. CrossRef Medline

Wallace LJ, Hughes RM (2008) Computational analysis of stimulated dopaminergic synapses suggests release largely occurs from a single pool of vesicles. Synapse 62:909-919. CrossRef Medline

Wightman RM, Zimmerman JB (1990) Control of dopamine extracellular concentration in rat striatum by impulse flow and uptake. Brain Res Brain Res Rev 15:135-144. CrossRef Medline

Wightman RM, Heien ML, Wassum KM, Sombers LA, Aragona BJ, Khan AS, Ariansen JL, Cheer JF, Phillips PE, Carelli RM (2007) Dopamine release is heterogeneous within microenvironments of the rat nucleus accumbens. Eur J Neurosci 26:2046-2054. CrossRef Medline

Wu Q, Reith ME, Wightman RM, Kawagoe KT, Garris PA (2001) Determination of release and uptake parameters from electrically evoked dopamine dynamics measured by real-time voltammetry. J Neurosci Methods 112:119-133. CrossRef Medline

Zald DH, Cowan RL, Riccardi P, Baldwin RM, Ansari MS, Li R, Shelby ES, Smith CE, McHugo M, Kessler RM (2008) Midbrain dopamine receptor availability is inversely associated with novelty-seeking traits in humans. J Neurosci 28:14372-14378. CrossRef Medline

Zhang H, Sulzer D (2004) Frequency-dependent modulation of dopamine release by nicotine. Nat Neurosci 7:581-582. CrossRef Medline

Zhou Y, Bunney BS, Shi WX (2006) Differential effects of cocaine on firing rate and pattern of dopamine neurons: role of alphal receptors and comparison with L-dopa and apomorphine. J Pharmacol Exp Ther 317: 196-201. CrossRef Medline 